Ben Richard Hughes, S.A.A. Abdul Ghani, A numerical investigation into the effect of windvent dampers on operating conditions, Building and Environment, Volume 44, Issue 2, February 2009, Pages 237-248, ISSN 0360-1323, http://dx.doi.org/10.1016/j.buildenv.2008.02.012.

\title{
A Numerical Investigation into the Effect of Windvent Dampers on Operating Conditions
}

\author{
Ben Richard Hughes and S A A Abdul Ghani
}

\author{
Sheffield Hallam University \\ Faculty of Arts, Computing, Engineering and Sciences \\ Materials and Engineering Institute \\ Sheffield, South Yorkshire \\ United Kingdom \\ S1 $1 \mathrm{WB}$
}

Keywords: - CFD, buildings, passive ventilation, natural ventilation, sustainable resources

\begin{abstract}
The United Kingdom has made a commitment to reduce buildings carbon emissions, placing a greater onus on sustainable energy sources. Therefore an anticipated increase of usage of zero carbon technologies in new and existing building has led to the emergence of passive ventilation devices as an alternative to mechanical ventilation and air conditioning. The Windvent is a commercially available passive ventilation device. The device is constructed from sheet metal and works on the principle of pressure differential. Whereby air rises, creating a low pressure in the receiving room, which then draws in the fresh air. The ensuing air delivery velocity is controlled by the dampers, installed at the room entry interface. The dampers are actuator operated, and form the basis of the control system for the device. The purpose of this paper is to investigate the control mechanism for the device and ascertain an optimum operating range. Numerical analysis is carried out using a commercial Computational Fluid Dynamics (CFD) code, to investigate the effect of various damper angles (range 0 - 90 degrees). The results show that optimum operating occurs at a damper angle range of 45 - 55 degrees, at the UK average $4.5 \mathrm{~m} / \mathrm{s}$ external wind speed. The operating range when considered in tandem with macro climatic influences is central to determining the overall control strategy for the fresh air supply. The results provide useful information for both engineers and architects when examining ways to reduce new and existing buildings running costs, and conform to new legislation.
\end{abstract}




\subsection{Introduction}

Sustainability is becoming a more prominent component of modern day building design. Many engineers and architects are coming under increased pressure to seek low carbon alternatives to traditional ancillary service supplies. The emergence of Sick Building Syndrome (SBS), which has been frequently linked to Heating Ventilation and Air Conditioning (HVAC) systems, has placed a greater emphasis on the overall turnover rate in fresh air exchange with the outside air.

It appears logical then that a natural ventilation system that is both sustainable and achieves the required air exchange rates would be a desirable option for modern day construction.

Natural ventilation has been largely ignored in the United Kingdom, due to mechanical devices that offer reliable guaranteed air exchange rates. However with the advent of increasing energy prices, and target reductions of carbon emissions, these ancient techniques have now become a serious alternative. One such natural ventilation technique is the Windvent, a device modelled on ancient Egyptian architecture, namely the Malkalf [1]. The Windvent sits on top of the building, trapping the air at higher velocity and delivering it into the interior of the building. The Windvent is divided into four quadrants, which allows fresh air to enter as well, as stale, or used, air to escape through the remaining quadrants.

The device combines the velocity, pressure, and density of air to produce the wind driven ventilation. This principle is encapsulated by Bernoulli's equation below;

Bernoulli's equation:

$\frac{1}{2} \rho V^{2}+P+\rho g h=$ Constant

Equation 1

Where;

$\rho \quad$ is the density

$\left(\mathrm{kg} / \mathrm{m}^{3}\right)$

$V \quad$ is the velocity

$P \quad$ is the pressure

$g \quad$ is the gravitational acceleration $\quad\left(\mathrm{m} / \mathrm{s}^{2}\right)$

$h \quad$ is the elevation

(m)

This equation is the fundamental equation necessary to understand and predict the behaviour of airflows in a building in terms of its natural environment [2]. 
Dampers are required to control the delivery rate of outside air, as fluctuations in external wind speed greatly affect the air movement rate within the occupied space. The authors [3] have highlighted the necessity of the damper arrangement, and that an effective control strategy requires further investigation. As can be seen in Bernoulli's equation, pressure and velocity are key to the operation of the device.

The numerical simulation procedure used in this study is described. The results of varying the angle of the dampers on the pressure and velocity, is simulated so as to achieve an optimum operating range for the control system.

\subsection{Previous related work}

Natural ventilation has been the subject of extensive research, however information relating to the performance of specific macro-micro climate interfaces is less common. Having established the role of standard numerical formula in the behaviour of air flows, it is sensible to start research in this area.

Hunt and Linden [4] investigated natural ventilation, specifically buoyancy driven flows assisted by wind. A Comparison of theoretical and experimental results established a Pythagorean relationship between combined buoyancy and wind effects.

Drori and Ziskind [5] used CFD and experimental studies to examine the effects of induced natural ventilation in Iran using a passive solar system for natural ventilation. The system achieved relative success and showed good correlation between both methods of analysis.

Priyadarsini et al. [6] also used CFD and experimental tools to analyse the different effects of passive and active (fan-assisted) stack systems in Singapore. The active stack in their study proved to be more successful at air distribution, again with good correlation between the numerical simulations and experimental measurements.

Elamualim [7] studied a similar wind catcher device, including dampers, diffuser, and a heat source to assess the ventilation capabilities of the device. The results yielded a good correlation between the numerical simulation and experimental measurements.

Elamualim [8] investigated a control strategy, which combined a wind catcher and hybrid air conditioning unit. The purpose of the investigation was to assess the contribution of the device to indoor air environment and energy savings. Whilst the control strategy employed failed to record operational data, it highlighted the need for careful planning of the strategy at the design and implementation stage.

Hughes and Ghani [3] investigated the effects of varying external wind conditions on the Windvents ability to supply outside air at the recommended rates. The results showed that the device is capable of delivering the required air exchange. The study also highlighted the role of the dampers as integral to the success of the device. The research has established the effectiveness of CFD as a numerical tool for this type of device and as such has been used for the purpose of this paper. Although previous work has yielded useful results, it did not investigate the effect of damping the performance of the device, or control strategy respectively. 
Liu and Mak[9] assessed the performance of a windcatcher system using CFD. The study used different wind directions and velocities to ascertain the effectiveness of the device for providing sufficient fresh air delivery. The results were validated against published experimental data and showed good correlation, and that the CFD techniques employed were appropriate for this type of device.

Yuehong et al.[10] used experimental and CFD techniques to ascertain the flow rates through a windcatcher device. This work investigated the flow rates through a windcatcher using CFD and experimental techniques with the results validated against published experimental work. The work highlights the good correlation between the CFD prediction and the experimental work and reinforces the effectiveness of CFD as a prediction tool in this area of research.

This paper shows the effect of varying the angle of the dampers of a Windvent on flow rates and pressure differentials achieved inside a controlled volume. Utilising 19 different CFD models, the angle of the dampers moved round by five degrees each time, for a range of 0 - 90 degrees. The external wind velocity was set at $4.5 \mathrm{~m} / \mathrm{s}$, as this is the UK average wind speed [11].

\subsection{CFD set-up}

The CFD model was developed using FLUENT, a commercially available general-purpose code. This code uses the finite volume method approach and employs the Semi-Implicit Method for Pressure-Linked Equations Consistent (SIMPLEC) velocity-pressure coupling algorithm. The turbulent nature of the flow is modelled by the standard $k-e$ model. The governing equations are the Navier-Stokes and energy equation which will not be repeated here but are available in detail in [12].

The windvent Geometry was created using Proengineer software and then imported into GAMBIT (FLUENT pre-processor) which was used to create the additional geometry, with a $6000 \times 6000 \times 3000 \mathrm{~mm}(500 \mathrm{~mm}$ false ceiling height $)$ micro climate representing a small classroom. The windvent geometry as illustrated in figure 3 was a $1000 \times 1000 \mathrm{~mm}$ windvent including cross dividers and damper faces, centrally placed above the room. In order to obtain sufficient distance between boundary conditions the macro climate was sized appropriately [13] and consists of a $6000 \times 6000 \times 4000 \mathrm{~mm}$ volume placed directly above the microclimate, thus creating a direct interface through the wind catcher geometry.

The dampers are four in total $(1000 \times 230 \mathrm{~mm})$, with a zero thickness. The dampers are rotated about a central axis to the desired angle, each model has varied damper angle in increments of 5 degrees.

\subsection{Boundary conditions}

Figure 1 shows the diffuser or egg crate grill which has been modelled using the porous jump boundary condition, which acts as thin membrane or filter with user defined inputs of permeability and medium thickness. A tertiary term of pressure jump coefficient is available to the user for this type of boundary condition shown in equation 2 however as a reliable coefficient is currently unavailable, the software reduces to the Darcy's law in the absence of this input [12]. 


$$
\Delta p=-\left(\frac{\mu}{\alpha} v+C_{2} \frac{1}{2} \rho v^{2}\right) \Delta m
$$

Equation 2

\section{Where;}

$\alpha \quad$ is the permeability of the medium

$\left(m^{2}\right)$

$\mathrm{C}_{2} \quad$ is the pressure-jump coefficient

$\Delta p \quad$ is the pressure drop across the medium

$\mu \quad$ is the laminar fluid viscosity

$(\mathrm{kg} / \mathrm{ms})$

$\Delta \mathrm{m} \quad$ is the thickness of the medium

(m)

$\rho \quad$ is the fluid density

$\left(\mathrm{kg} / \mathrm{m}^{3}\right)$

$v \quad$ is the fluid velocity

$(\mathrm{m} / \mathrm{s})$

The diffuser is the final interface between the macro and micro climate, and the recorded average velocity cross this face is used to determine the delivery velocity in the results section of this paper.

The macro climate created, to simulate the incident wind velocity may be seen in figure 2 , consists of a velocity inlet (value of $4.5 \mathrm{~m} / \mathrm{s}$ ) at one complete side, and a pressure outlet (atmospheric pressure) on the opposing side. The remainder of the macro climate faces were named as symmetry faces, thus alleviating any return velocities which may distort the results.

Top Hat

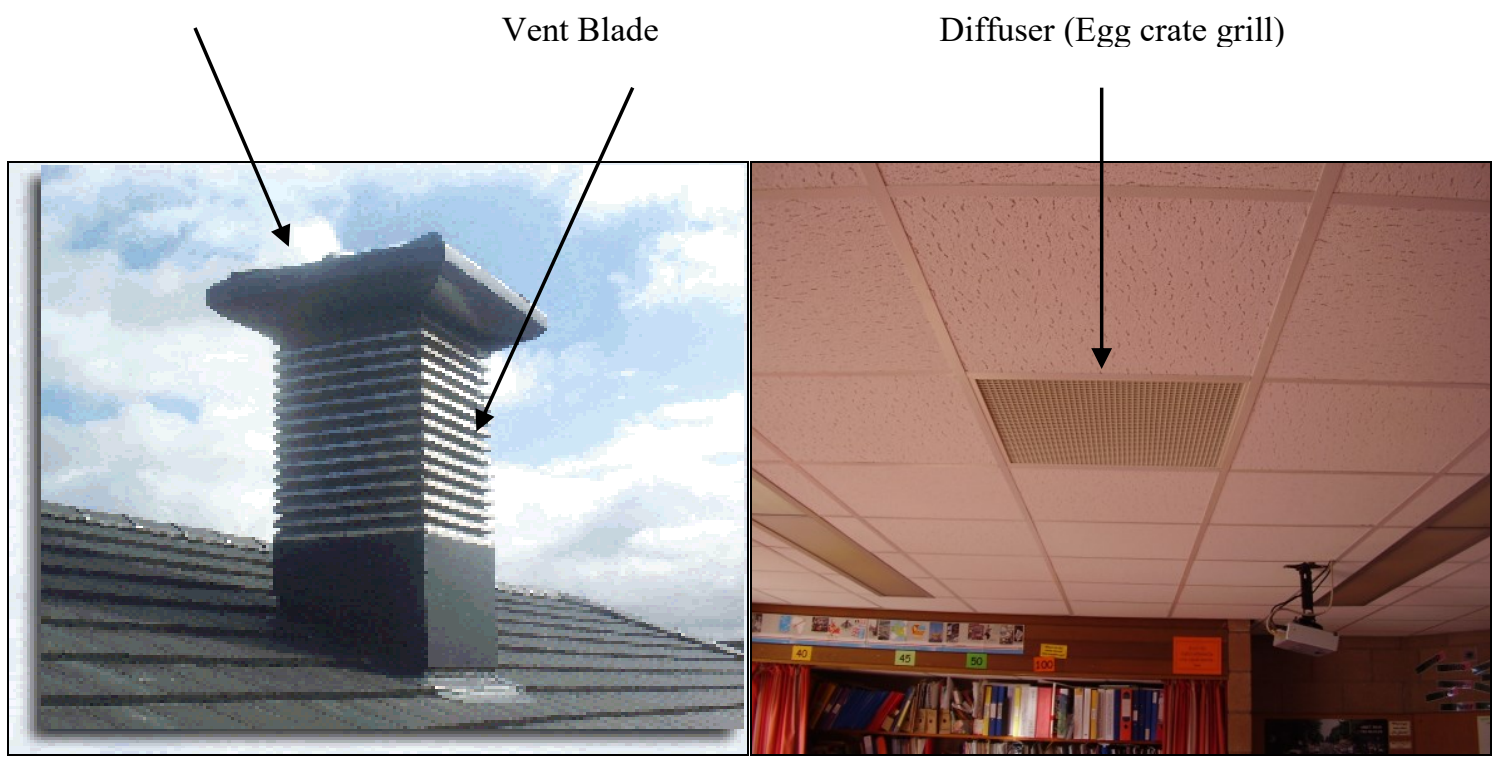

Figure 1 Windvent and Diffuser - Courtesy of Midtherm Engineering 


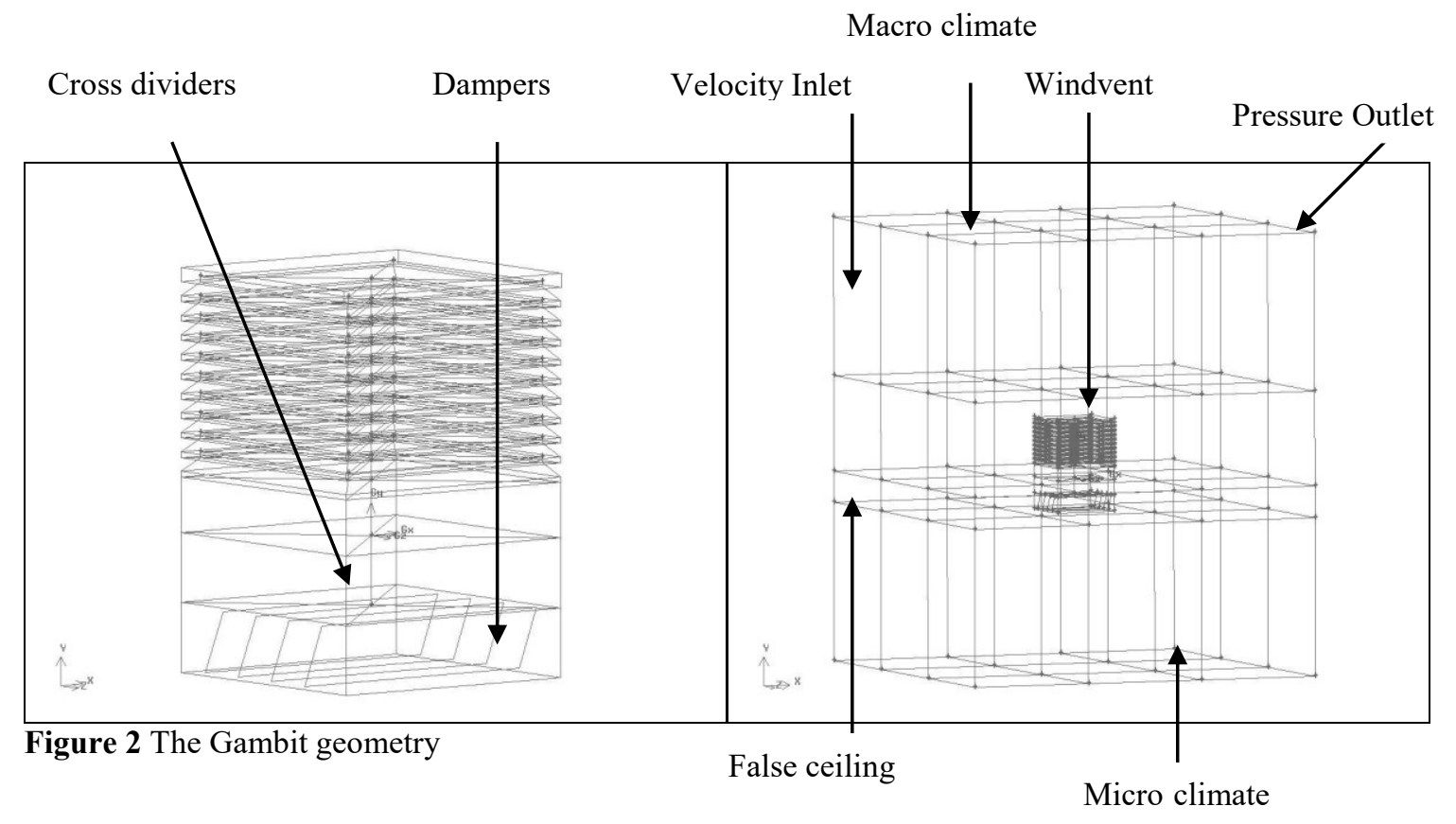

The dampers were created as faces. They were rotated to the desired angle by using two centrally placed vertices to form a central axis. The pressure faces ( $\mathrm{P} 1$ and $\mathrm{P} 2$ ) were named as interior faces.

Wind vent dampers

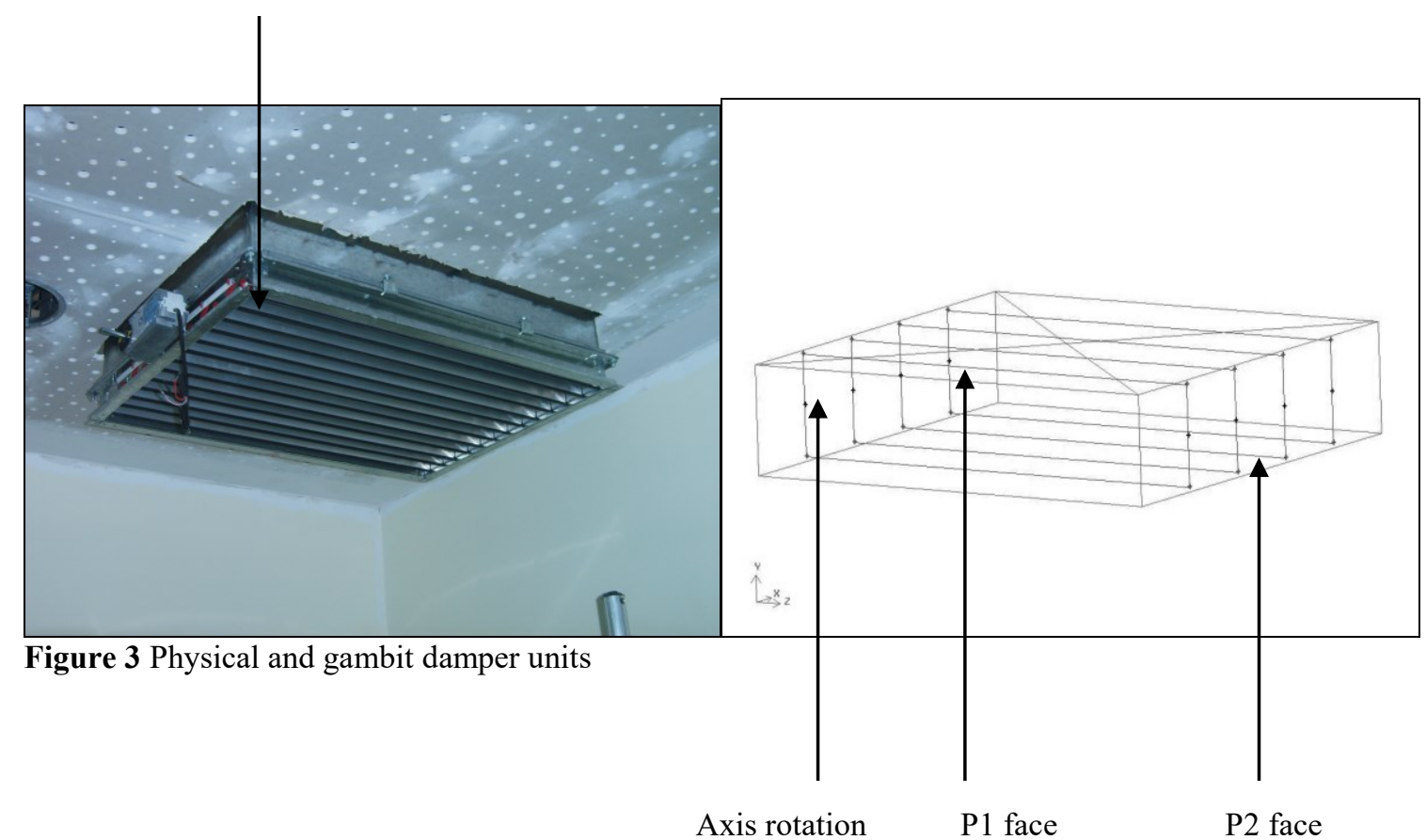




\subsection{Grid adaption}

Due to the geometrical complexity, the computational mesh was generated using triangular elements. In order to accurately resolve the solution fields, the grid was refined and enriched using the $h p$-method [13]. This process of adaption requires a decision as to the usage of $h$-refinements (the mesh size) or $p$-enrichments (higher order approximations) by the use of a posteriori error estimate.

The posteriori estimate used in the developed model is the average weighted velocity taken on the face between the windvent and the micro climate. An initial coarse grid was evaluated, and subsequent refinements were evaluated until the error deemed negligible between refinements. When refining the grid it is important to note that a compromise must be reached, between accuracy and computational time. The boundary conditions remain fixed throughout this process to ensure accurate comparison of the error indicator.

\section{Grid Adaption}

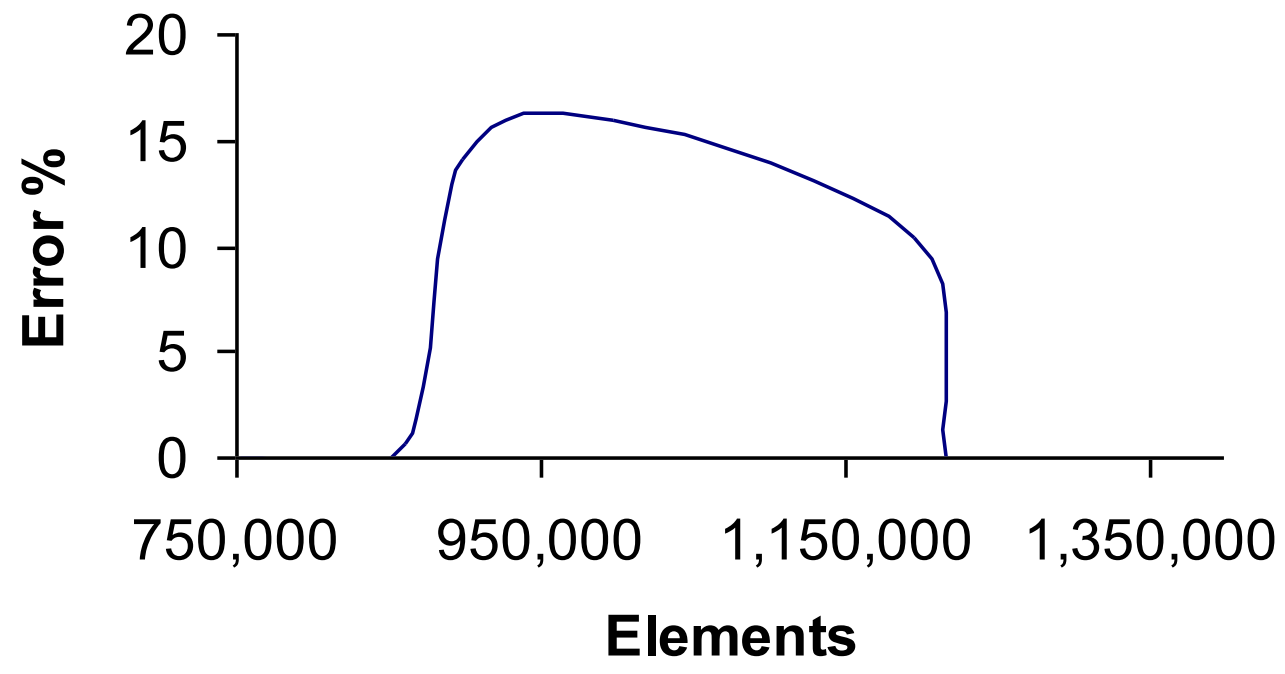

Figure 4 Graph to highlight the percentage error reduction through grid refinements

The initial coarse grid consisted of 860,166 elements which was refined over three stages until an acceptable error of $0.01 \%$ was achieved with a total of $1,216,987$ elements. The model was split into three areas, Windvent (stage 1), Macro climate (stage 2), and micro climate (stage 3 ), and each area refined as illustrated in figures 6,8 and 10. 


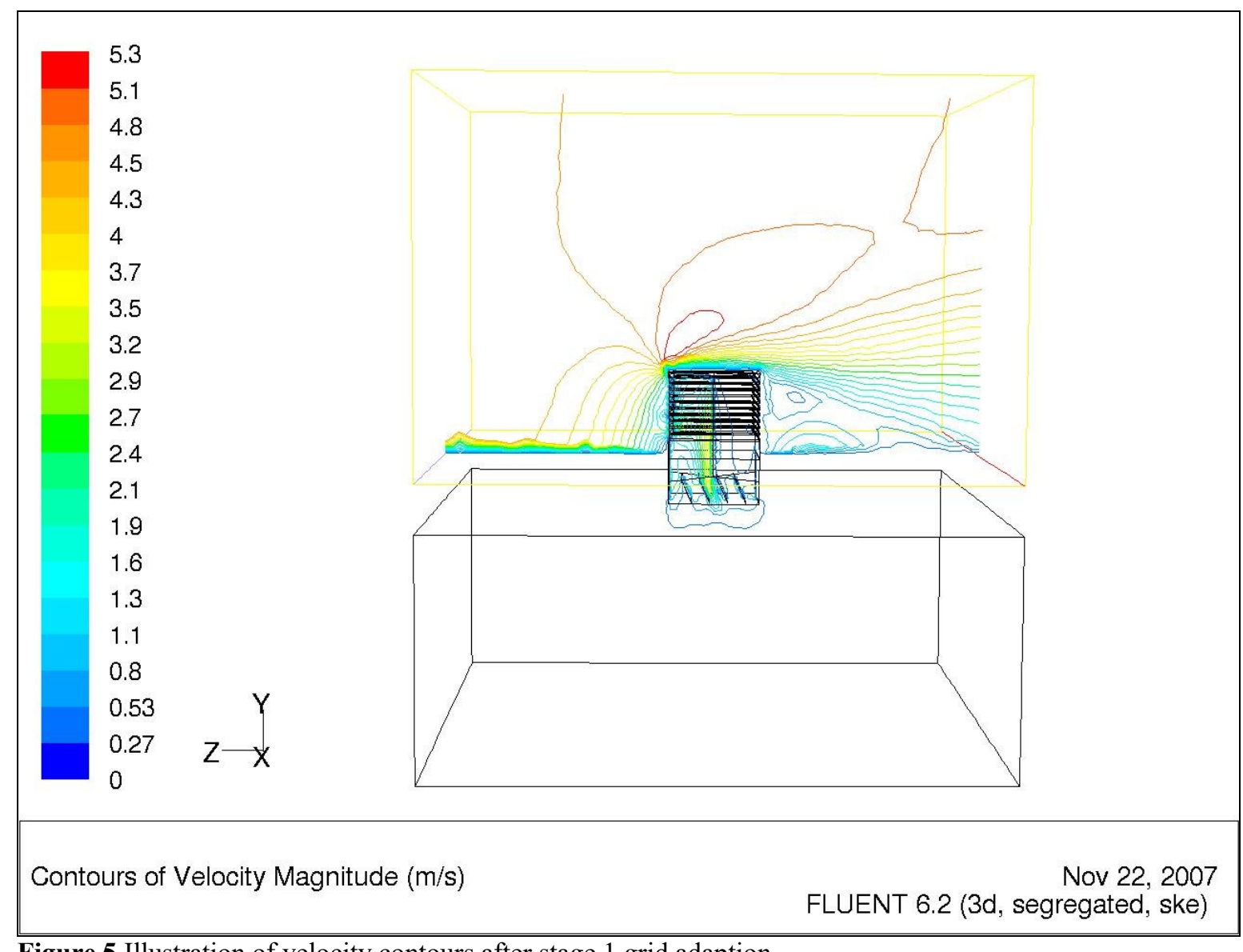

Figure 5 Illustration of velocity contours after stage 1 grid adaption

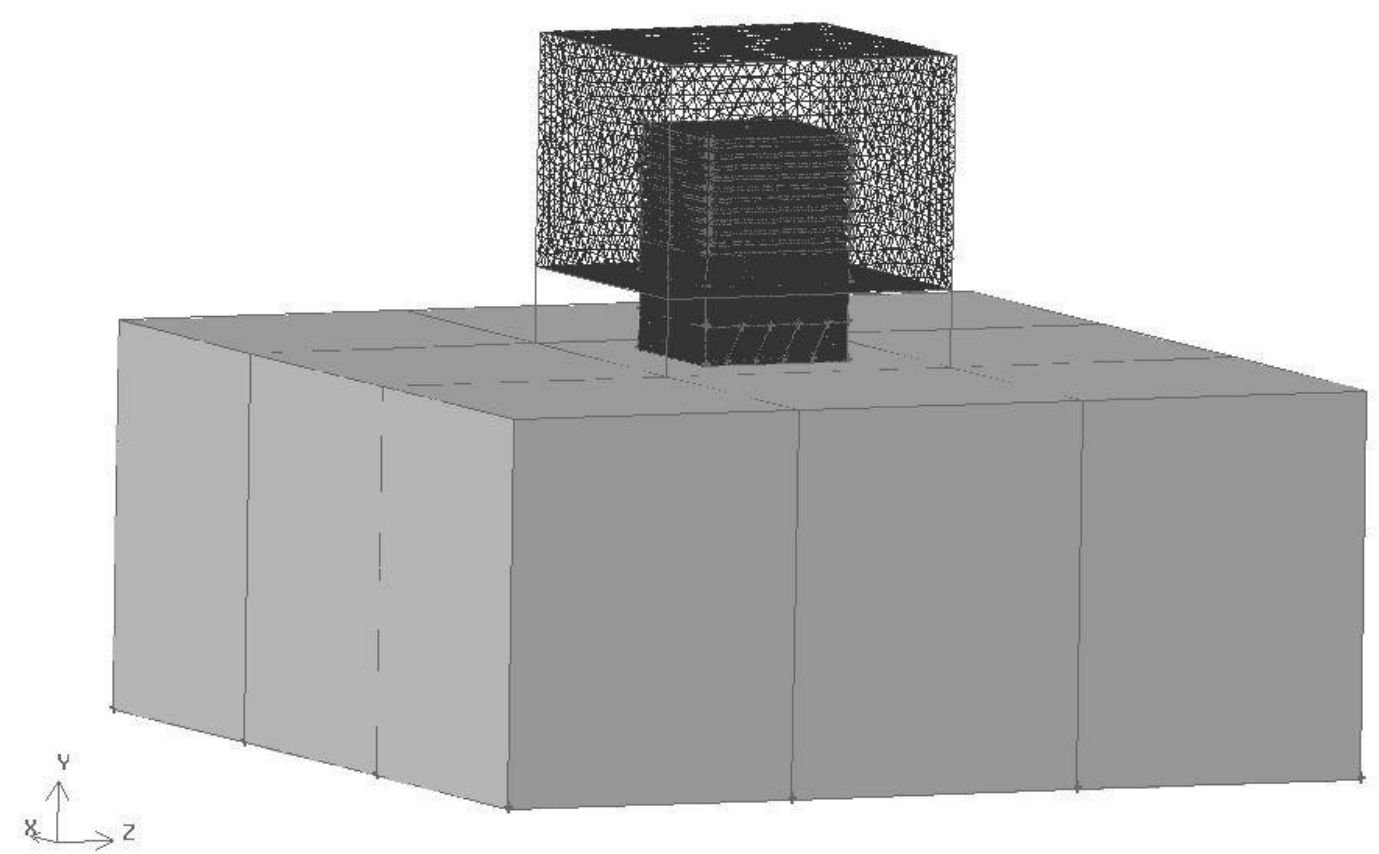

Figure 6 Illustration of the refined area, the Windvent geometry and surrounding volume. 
Stage 1 of the grid adaption concentrates on the windvent and immediate surroundings (as illustrated in figure 6), keeping the remaining grid sizes constant throughout the process. The velocity contour plot in figure 5 shows the separation of the velocity around the windvent, and the diffuser to micro climate. 


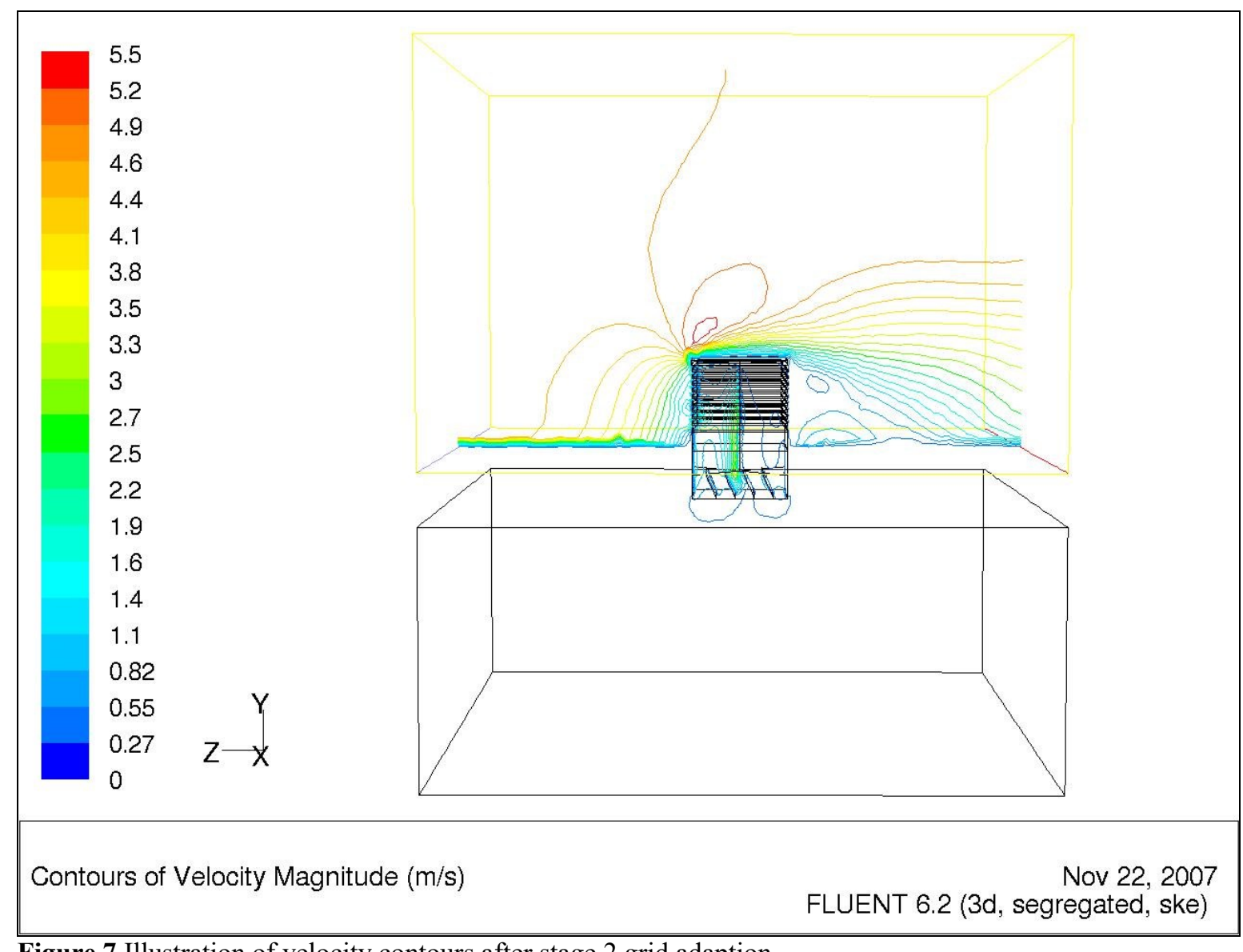

Figure 7 Illustration of velocity contours after stage 2 grid adaption
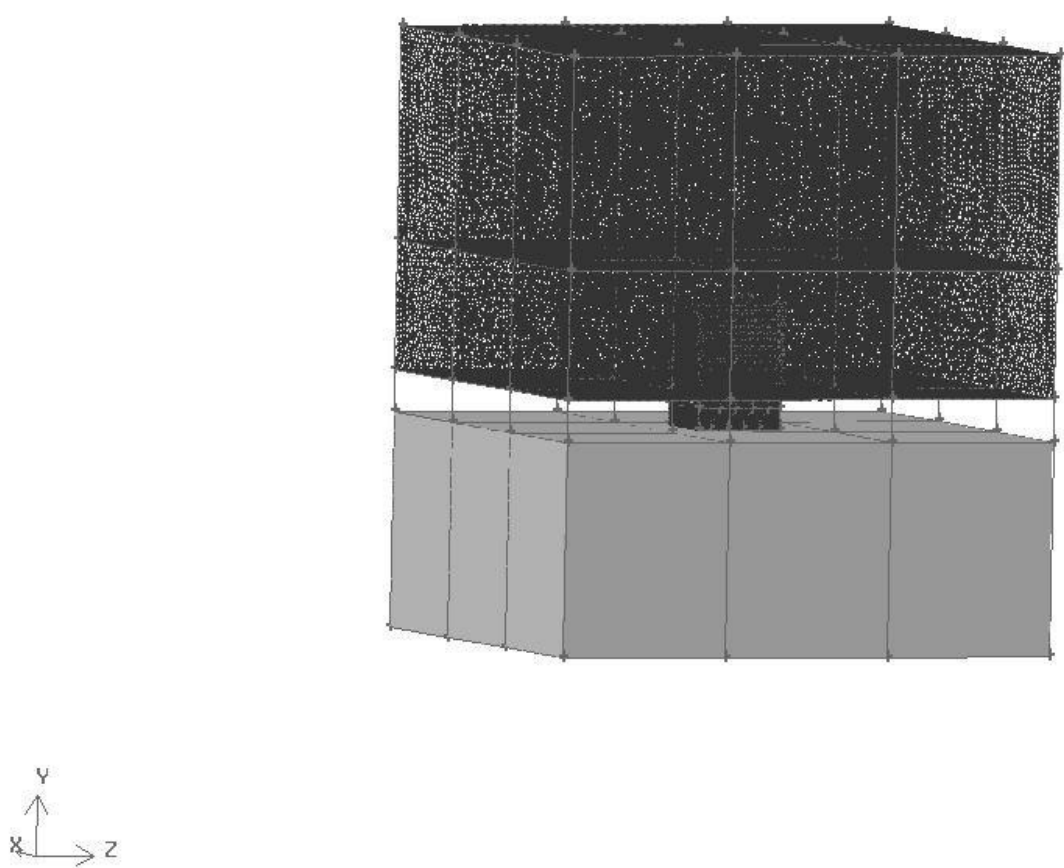

Figure 8 Illustration of the refined area, the macro climate. 
Stage 2 of the adaption concentrates on the macro climate leaving the remaining cell sizes constant (see figure 8). The velocity contour plot illustrates the separation of velocities is now more defined. The definition is evident at the diffuser to micro climate and also the velocity differences after the windvent and above respectively. 


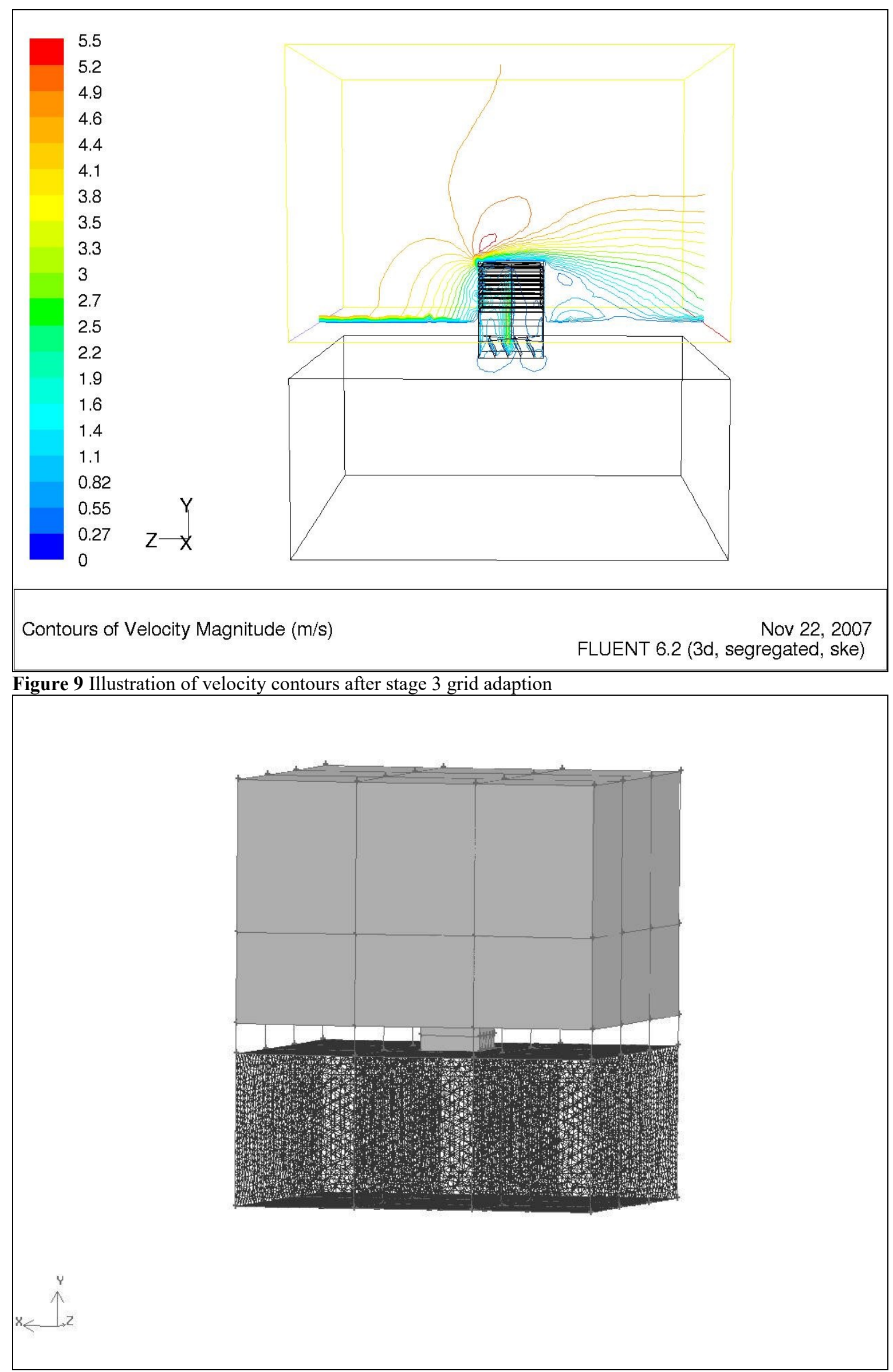

Figure 10 Illustration of the refined area, the micro climate. 
Stage 3 of the adaption concentrates on the micro climate leaving the remaining cell sizes constant. Once again the separation in the velocity contours is more defined than the previous refinement, although not to the same extent as this is the final stage of refinement.

Having achieved grid independency, the model was run for various wind directions and velocities, with the results presented in section 5.0.

\subsection{Validation}

The CFD results have been validated against recent research carried out by Elmualim(14) on a wind catcher by using both CFD and wind tunnel testing. The wind catcher used in the Elmualim study was of the same geometrical construction and the simulation utilising the same CF code and model set up. The results have been normalised for comparison as the wind catchers were of different over size ( 0.5 and 1 metre respectively).

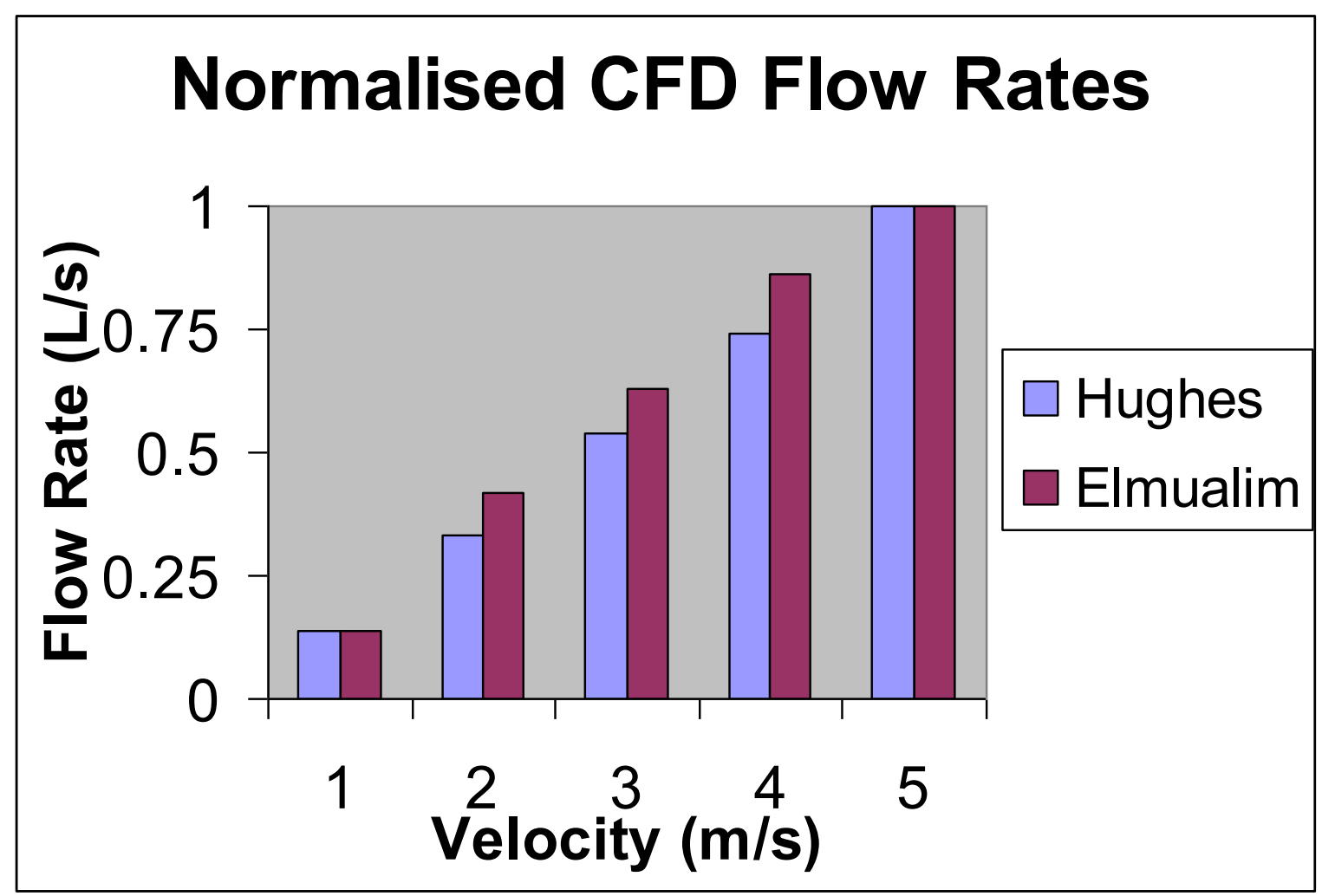

Figure 11 Comparison of normalised flow rates from the CFD results from the two studies 


\section{Normalised CFD Vs Experimental Flow Rates}

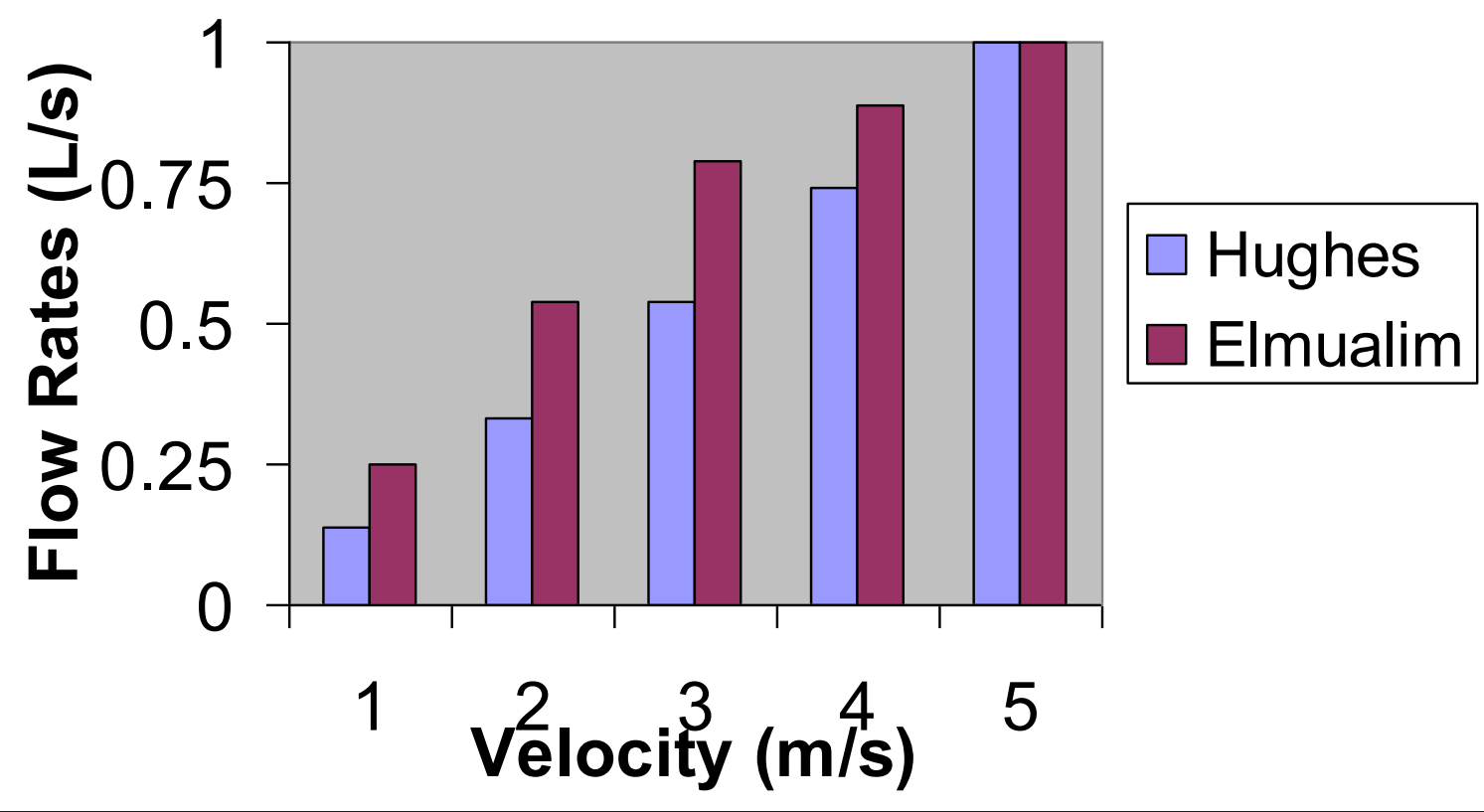

Figure 12 Comparison of normalised CFD results against published experimental data

As can be seen from figures 11 and 12 the CFD results in this study are similar (range 0 $30 \%$ error with an average of $20 \%$ error) in comparison to other published studies and therefore may be considered reliable. 


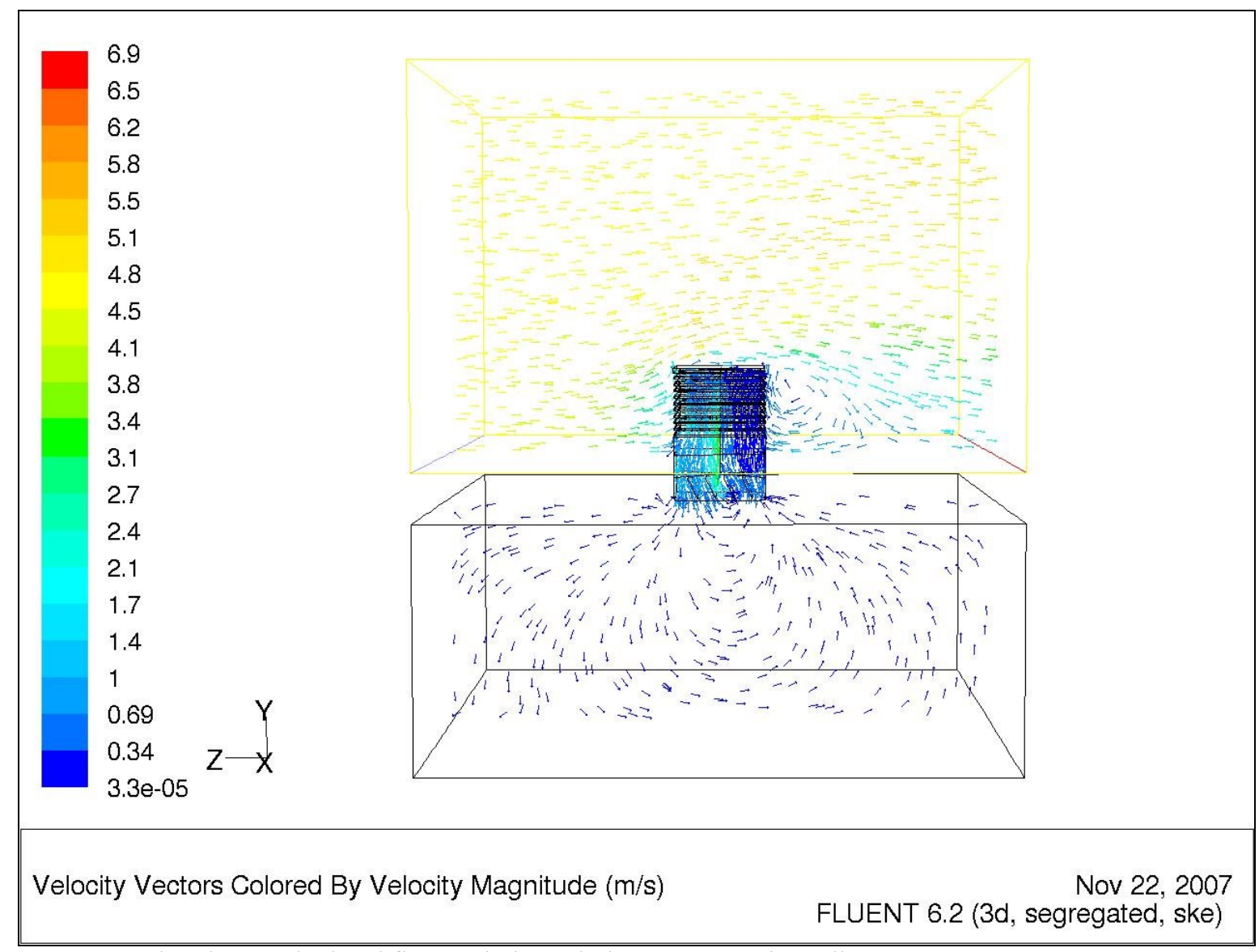

Figure 13 The Fluent calculated flow path through the macro to micro climate

Figure 13 is a vector plot which shows the flow entering from the left of the boundary velocity inlet, the flow splits with some of the air entering the interface and some passing over or shearing and exiting to the right (pressure outlet). The geometry shown includes a supplementary vertical plane created to assist in the illustrative analysis of the model. The flow entering the windvent, accelerates as it enters the device reaching maximum velocity as it hits the cross dividers and forces the flow down into the diffuser. As the air exits the diffuser into the micro climate it creates a horse shoe shaped pattern, as the pressure differential allows the flow in and also out of the device. Upon exiting the windvent the flow splits with some of the air recirculating and mixing with that of the spent air and the rest mixing with sheared air above the device. 

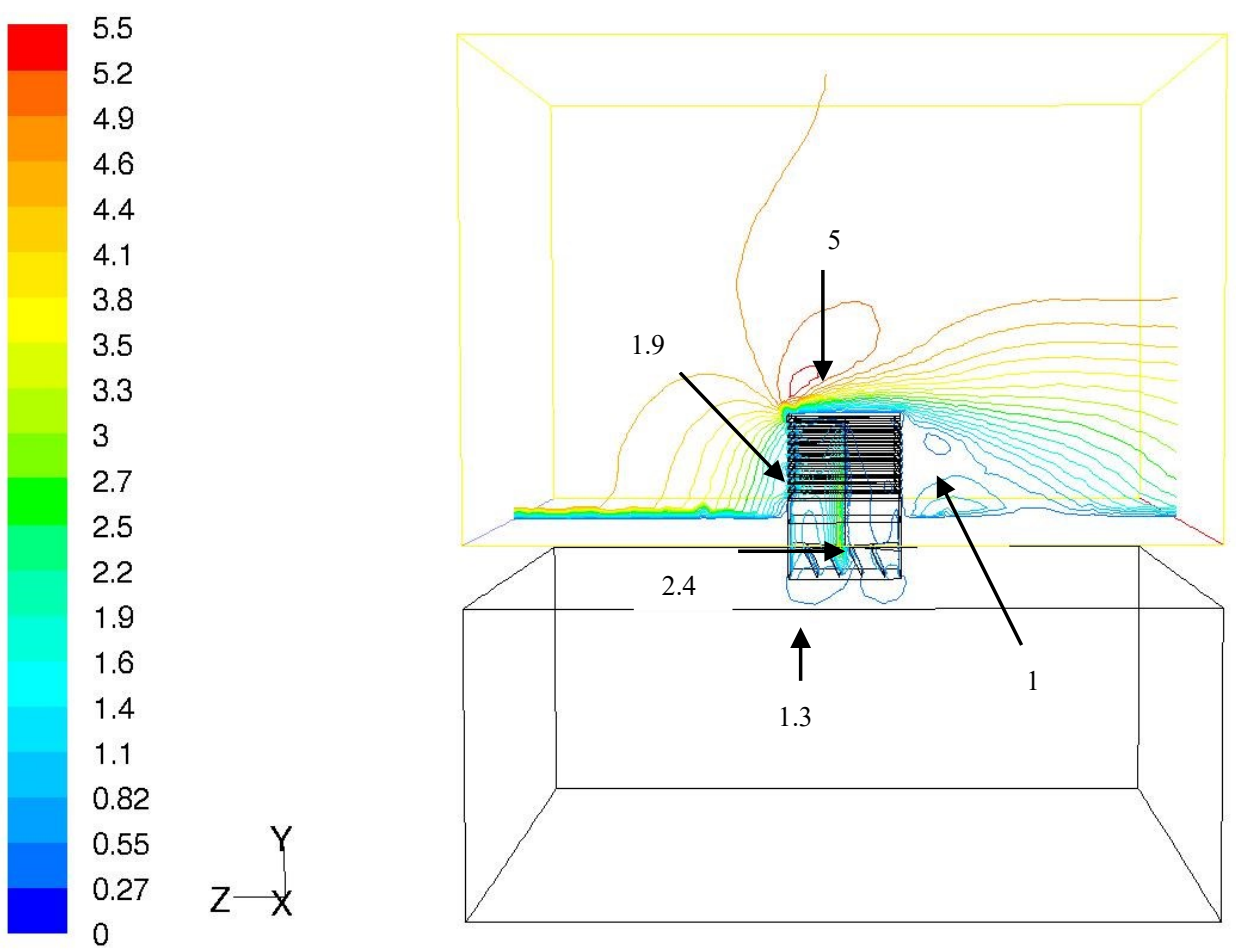

Contours of Velocity Magnitude (m/s)

Nov 22, 2007

FLUENT 6.2 (3d, segregated, ske)

Figure14 The Fluent calculated flow distribution illustrated by velocity contours

Figure 14 shows the supplementary face with the surrounding geometry. The vertical face cuts through the model through the centre to show an accurate cross section of the model, and assist the illustrative analysis. The flow is counter current with the direction of the dampers. 


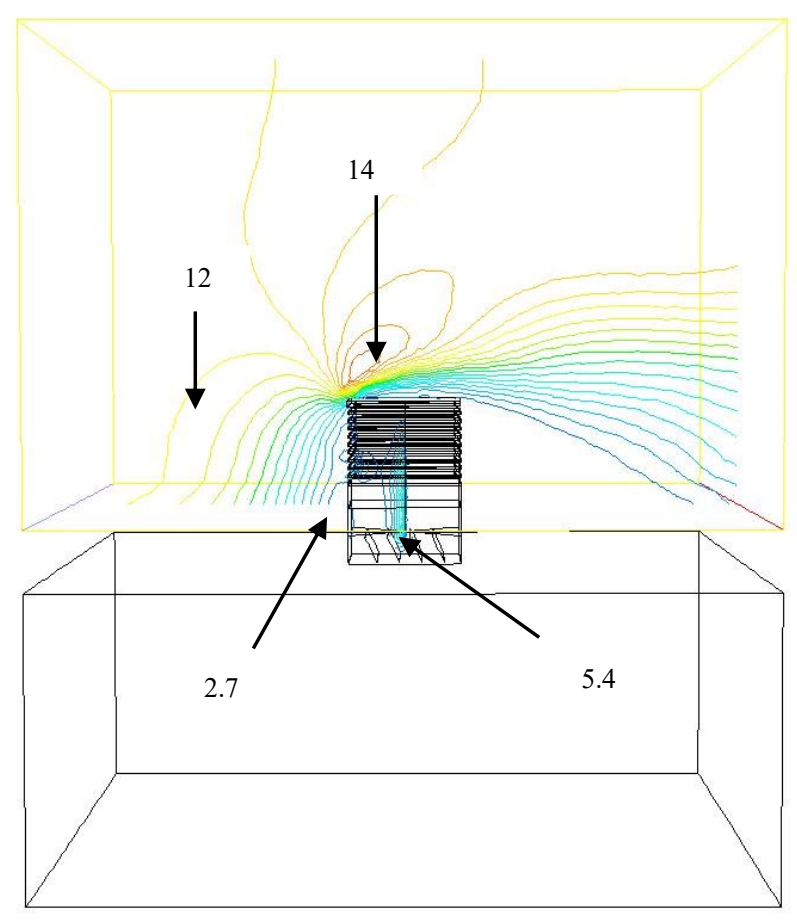

Contours of Dynamic Pressure (pascal)

Figure 15 The Fluent calculated pressure distribution through the computational domain

Figure 15 illustrates the pressure distribution through the cross section of the model. From the illustration it is seen that the areas of high pressure are around the Windvent and at the divider facing the direction (inlet) of the external wind. 

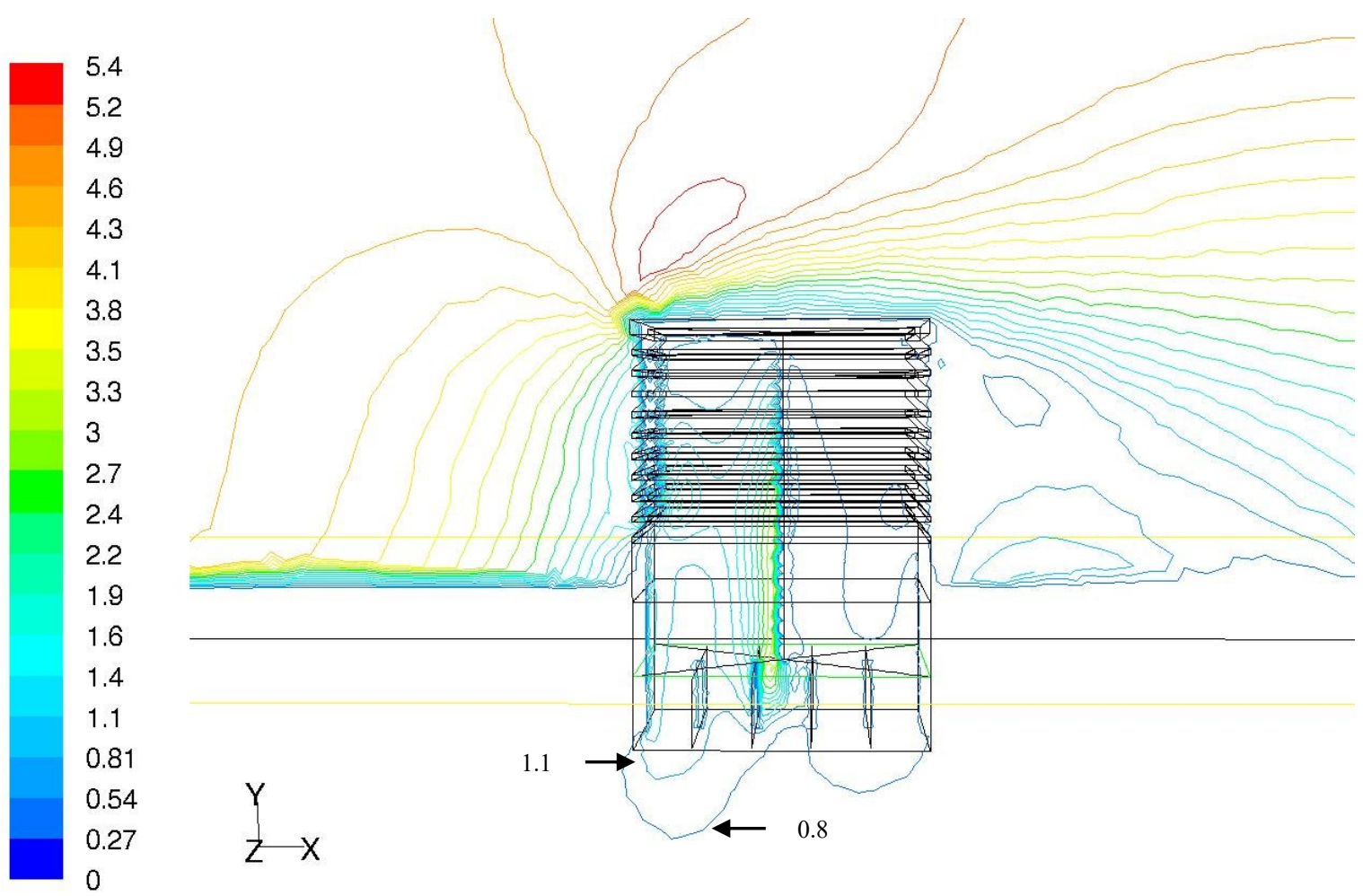

Contours of Velocity Magnitude $(\mathrm{m} / \mathrm{s})$

Nov 22, 2007

FLUENT 6.2 (3d, segregated, ske)

Figure 16 The Fluent calculated velocity contours of the Windvent with dampers fully open

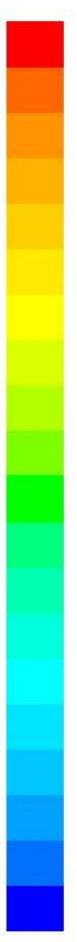

18
17
16
15
15
14
13
12
11
10
9.1
8.2
7.3
6.4
5.5
4.6
3.6
2.7
1.8
0.91

$6.7 \mathrm{e}-09$
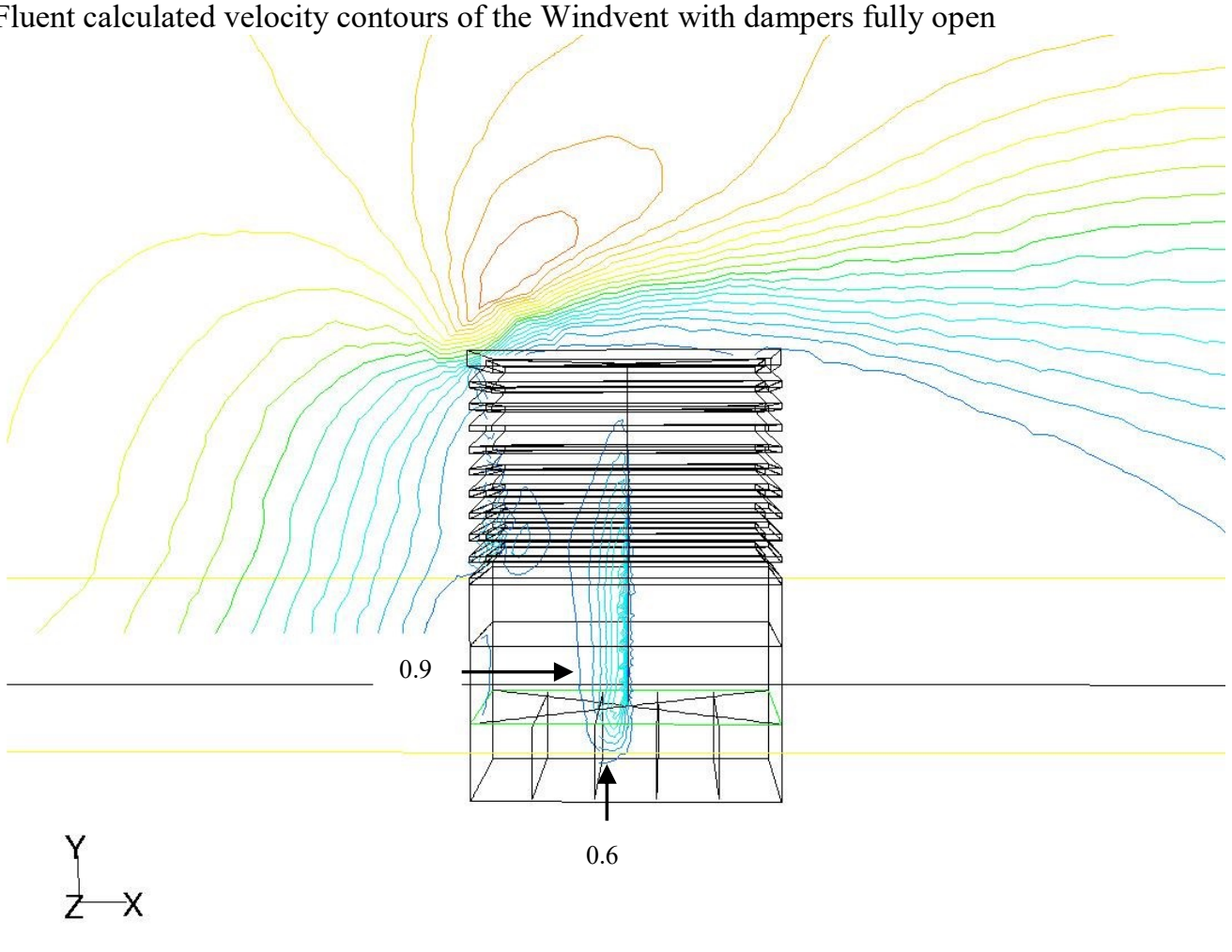

0.6

Contours of Dynamic Pressure (pascal)

Nov 22, 2007

FLUENT 6.2 (3d, segregated, ske)

Figure 17 The Fluent calculated pressure contours of the Windvent with dampers fully open 
Figure 16 is a close up view of the windvent air distribution with dampers fully open. As can be seen much of the flow exits the vent without entering the micro climate, a phenomenon known as short circuiting. Figure 17 shows the pressure distribution within the vent with the dampers fully open.
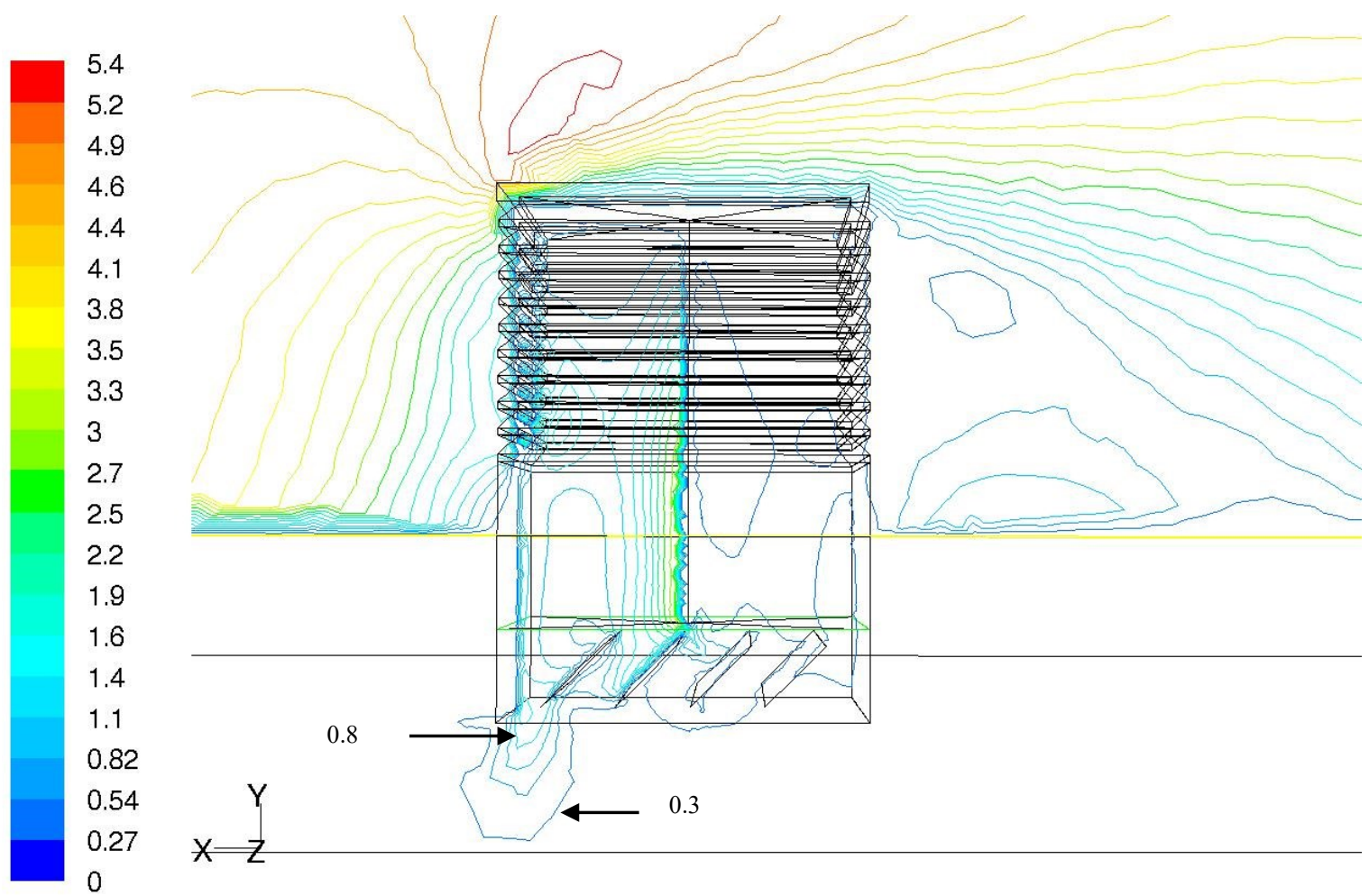

Contours of Velocity Magnitude $(\mathrm{m} / \mathrm{s})$

Nov 22, 2007

FLUENT 6.2 (3d, segregated, ske)

Figure 18 The Fluent calculated velocity contours of the Windvent with dampers at 45 degrees. 


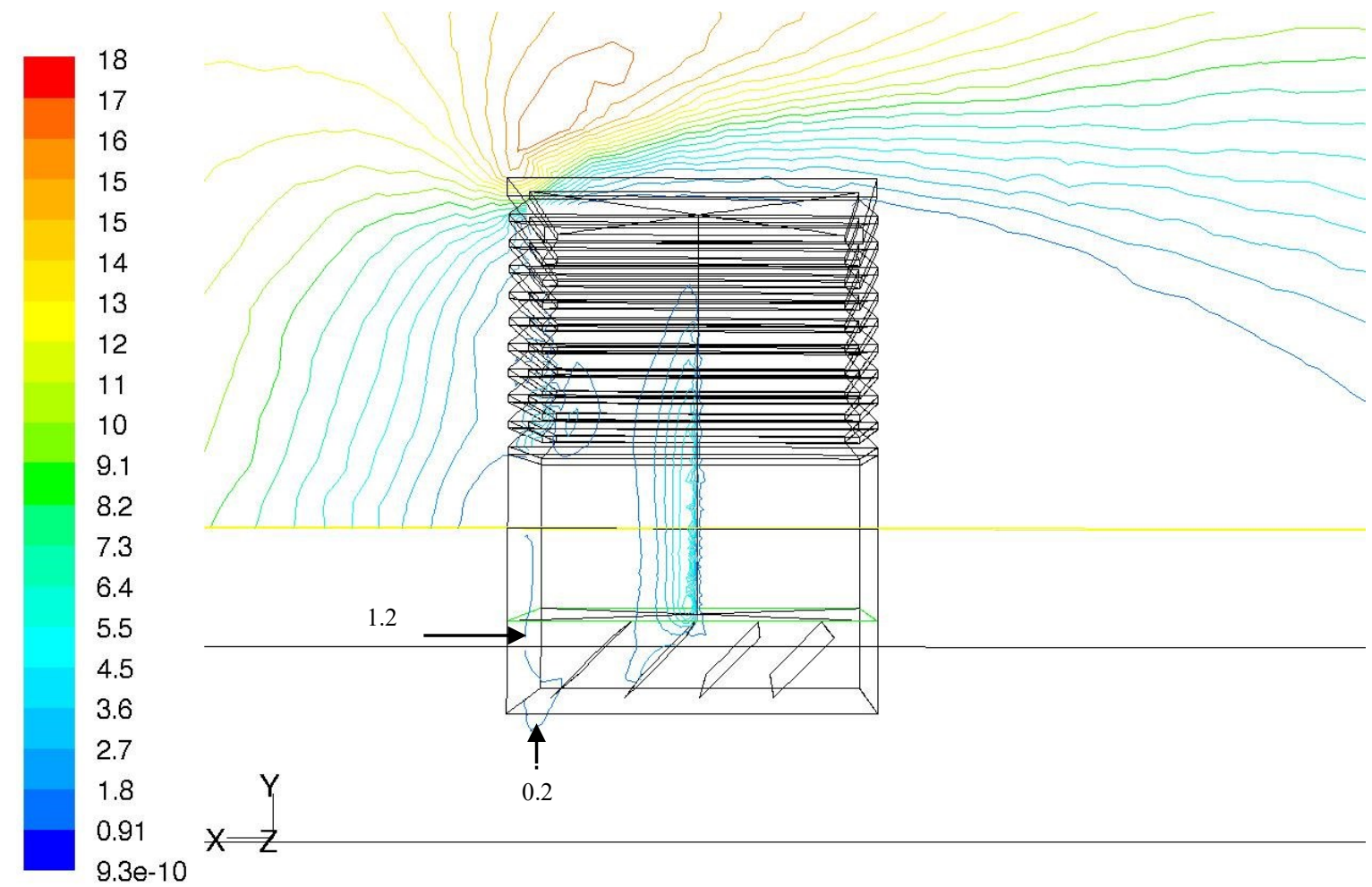

Contours of Dynamic Pressure (pascal)

Nov 22, 2007

FLUENT 6.2 (3d, segregated, ske)

Figure 19 The Fluent calculated pressure contours of the Windvent with dampers at 45 degrees

Figures 18 and 19 Shows the effect of partially closing the dampers on the velocity and pressure distribution. The velocity contours show that much less flow is short circuiting compared to figure 16. The pressure contours show the increased pressure around the damper faces (P1), and the pressure around the diffuser face (P2) has decreased. 

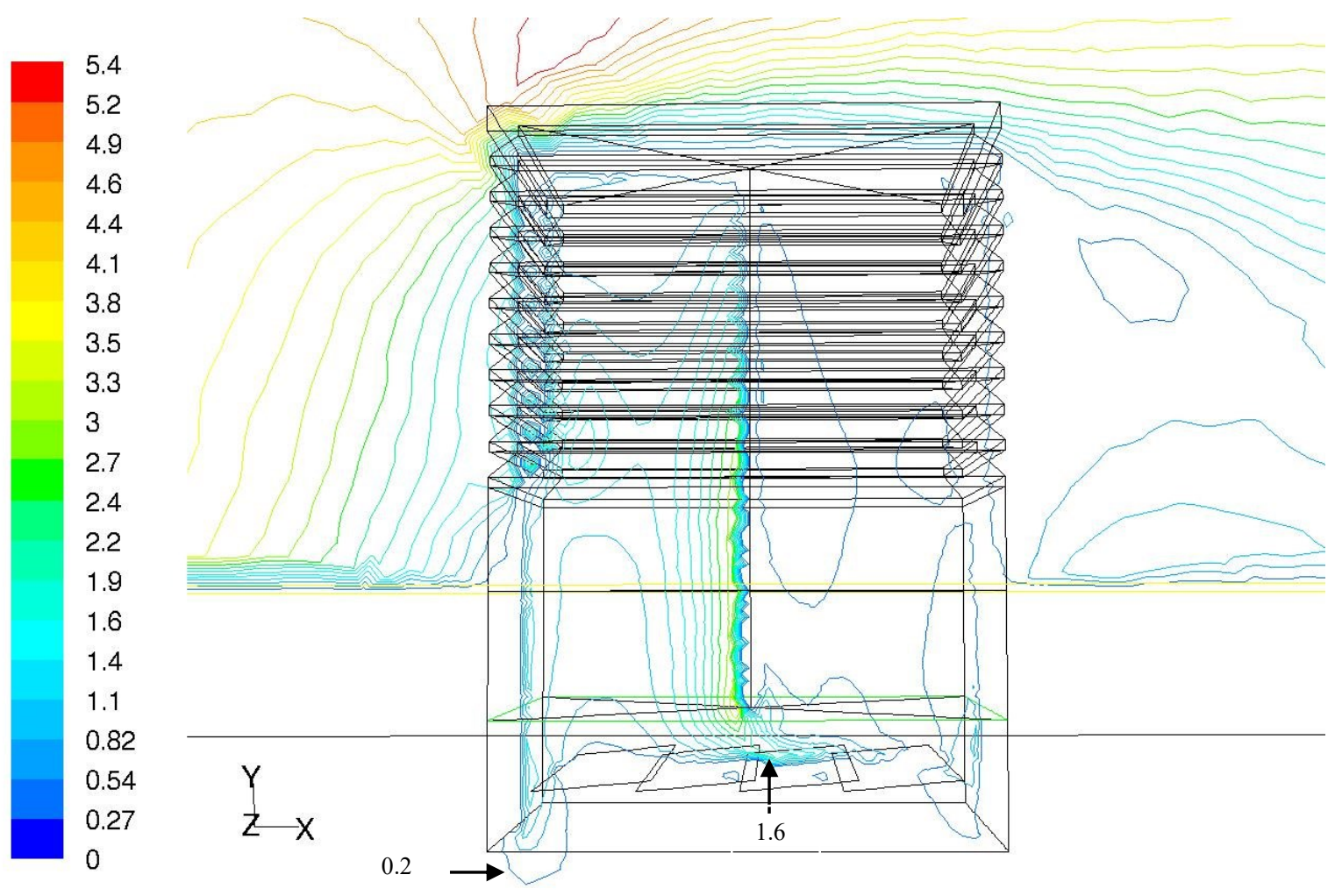

Contours of Velocity Magnitude $(\mathrm{m} / \mathrm{s})$

Nov 22, 2007

FLUENT 6.2 (3d, segregated, ske)

Figure 20 The Fluent calculated velocity contours of the Windvent with dampers at 85 degrees
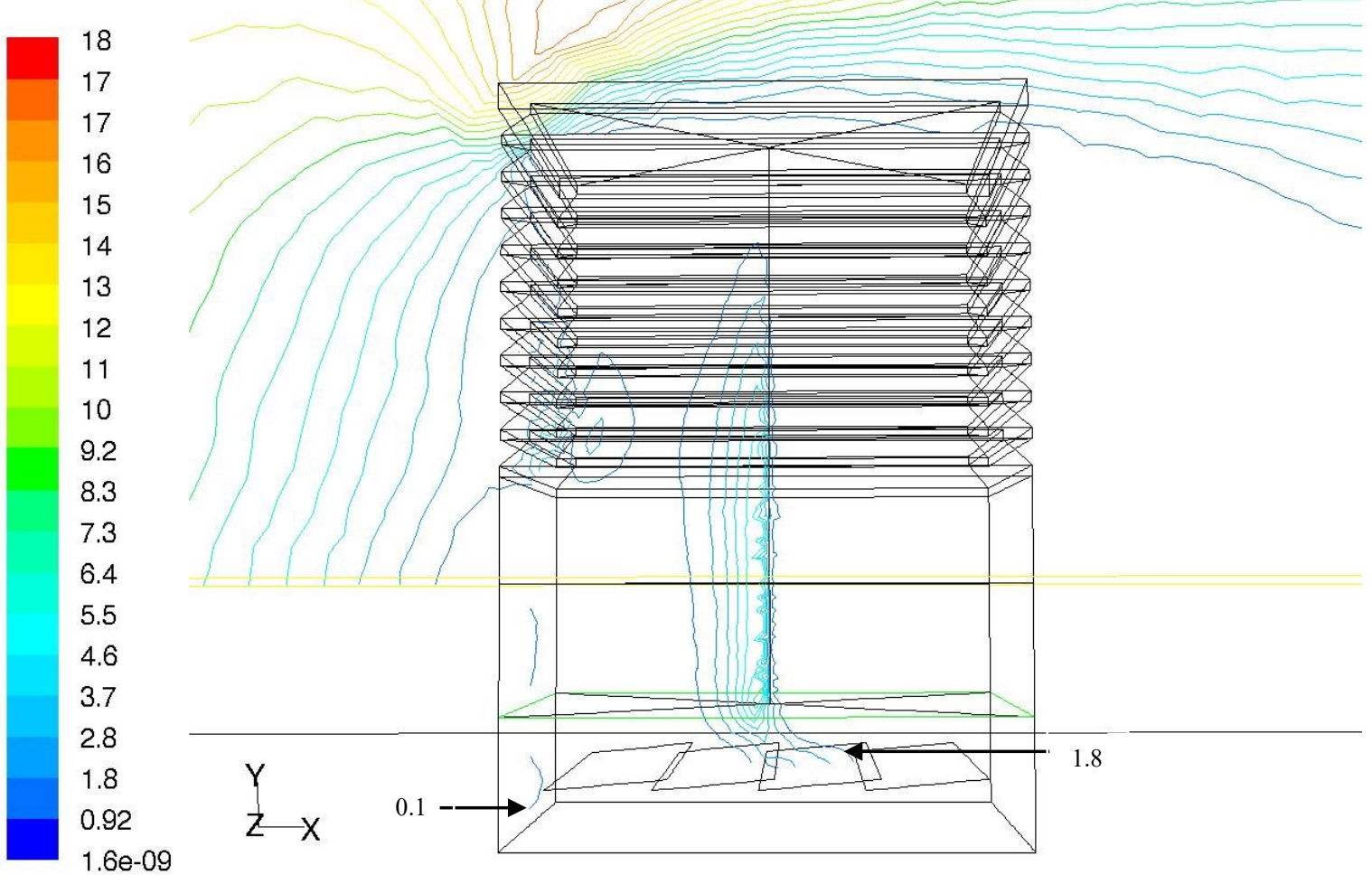

$1.6 \mathrm{e}-09$

Contours of Dynamic Pressure (pascal)

Nov 22, 2007

FLUENT 6.2 (3d, segregated, ske)

Figure 21 The Fluent calculated pressure contours of the Windvent with dampers at 85 degrees 
Figures 20 and 21 show the flow through the Windvent with the dampers almost fully closed. The velocity contours illustrate that there is now very little flow entering the micro climate. The pressure contours show the increased pressure on the dampers faces $(\mathrm{P} 1)$, and decreased pressure around the diffuser (P2).

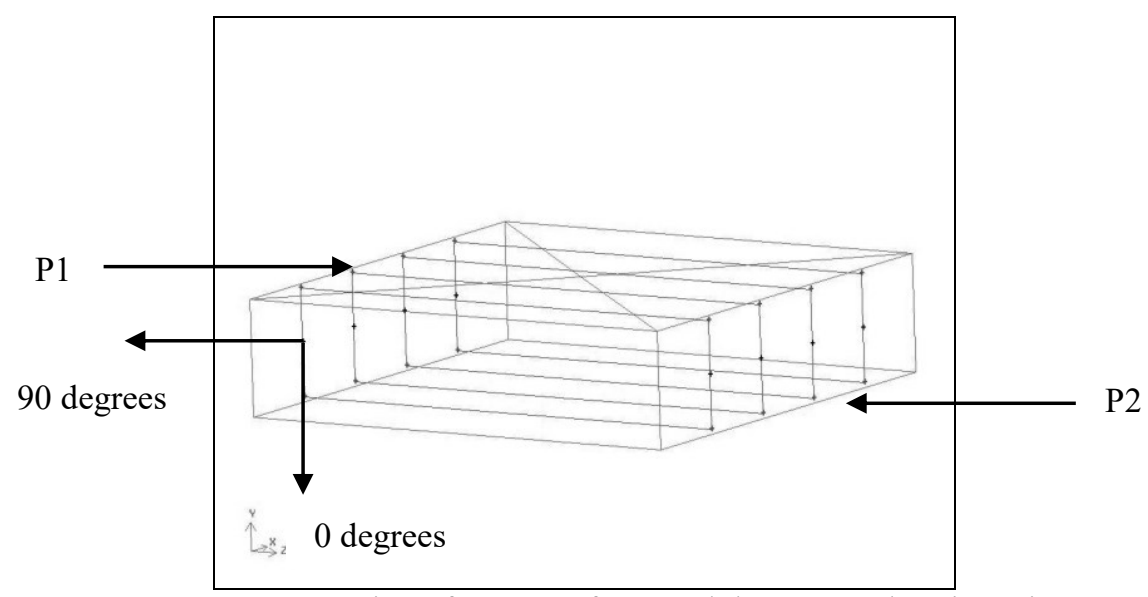

Figure 22 Location of pressure faces and damper angle orientation

\subsection{Results}

19 CFD cases run with different damper angles. All boundary conditions remained constant with the pressure and velocity differences noted. The full results are presented in tabular form followed by graphs of the velocity and pressure trends.

Table 1 Summary of results at dampers angle (0-90) degrees.

\begin{tabular}{|r|r|r|r|r|r|r|}
\hline $\begin{array}{l}\text { Damper } \\
\text { Angle }\end{array}$ & $\begin{array}{l}\text { Velocity } \\
\mathrm{m} / \mathrm{s}\end{array}$ & P1 Pressure & P2 Pressure & Pressure Drop & $\begin{array}{l}\text { Air } \\
\text { Supply } \\
\text { L/s per } \mathrm{m}^{2}\end{array}$ & $\begin{array}{l}\text { Air } \\
\text { Supply } \\
\text { L/s per } \\
\text { occupant }\end{array}$ \\
\hline 0 & 0.53 & 0.57 & 0.23 & 0.34 & 14.78 & 26.60 \\
\hline 5 & 0.54 & 0.59 & 0.24 & 0.35 & 15.14 & 27.24 \\
\hline 10 & 0.53 & 0.57 & 0.23 & 0.33 & 14.65 & 26.36 \\
\hline 15 & 0.52 & 0.57 & 0.24 & 0.34 & 14.46 & 26.03 \\
\hline 20 & 0.51 & 0.58 & 0.24 & 0.34 & 14.23 & 25.62 \\
\hline 25 & 0.50 & 0.59 & 0.24 & 0.35 & 13.92 & 25.05 \\
\hline 30 & 0.50 & 0.61 & 0.25 & 0.36 & 13.78 & 24.81 \\
\hline 35 & 0.47 & 0.60 & 0.24 & 0.37 & 13.07 & 23.52 \\
\hline 40 & 0.46 & 0.61 & 0.24 & 0.37 & 12.71 & 22.88 \\
\hline 45 & 0.42 & 0.62 & 0.22 & 0.40 & 11.74 & 21.13 \\
\hline 50 & 0.40 & 0.62 & 0.21 & 0.41 & 11.08 & 19.94 \\
\hline 55 & 0.38 & 0.63 & 0.21 & 0.43 & 10.66 & 19.19 \\
\hline 60 & 0.36 & 0.63 & 0.19 & 0.44 & 9.93 & 17.88 \\
\hline 65 & 0.34 & 0.63 & 0.18 & 0.46 & 9.52 & 17.13 \\
\hline 70 & 0.32 & 0.64 & 0.16 & 0.47 & 9.01 & 16.22 \\
\hline 75 & 0.31 & 0.64 & 0.15 & 0.49 & 8.68 & 15.62 \\
\hline 80 & 0.28 & 0.62 & 0.12 & 0.50 & 7.77 & 13.98 \\
\hline 85 & 0.26 & 0.64 & 0.10 & 0.53 & 7.09 & 12.77 \\
\hline 90 & 0.23 & 0.67 & 0.08 & 0.59 & 6.38 & 11.48 \\
\hline
\end{tabular}




\section{Pressure drop}

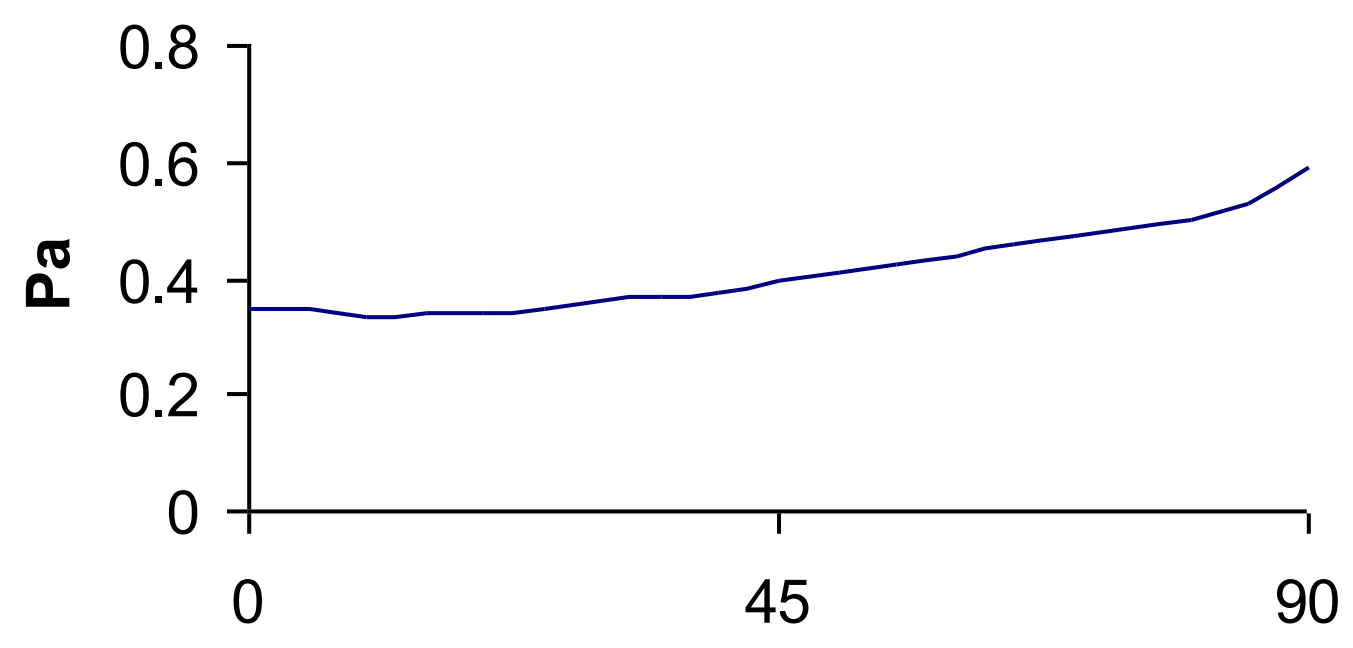

Damper angle

Figure 23 Effect on Windvent pressure drop by an increase in damper angle

\section{Velocity drop}

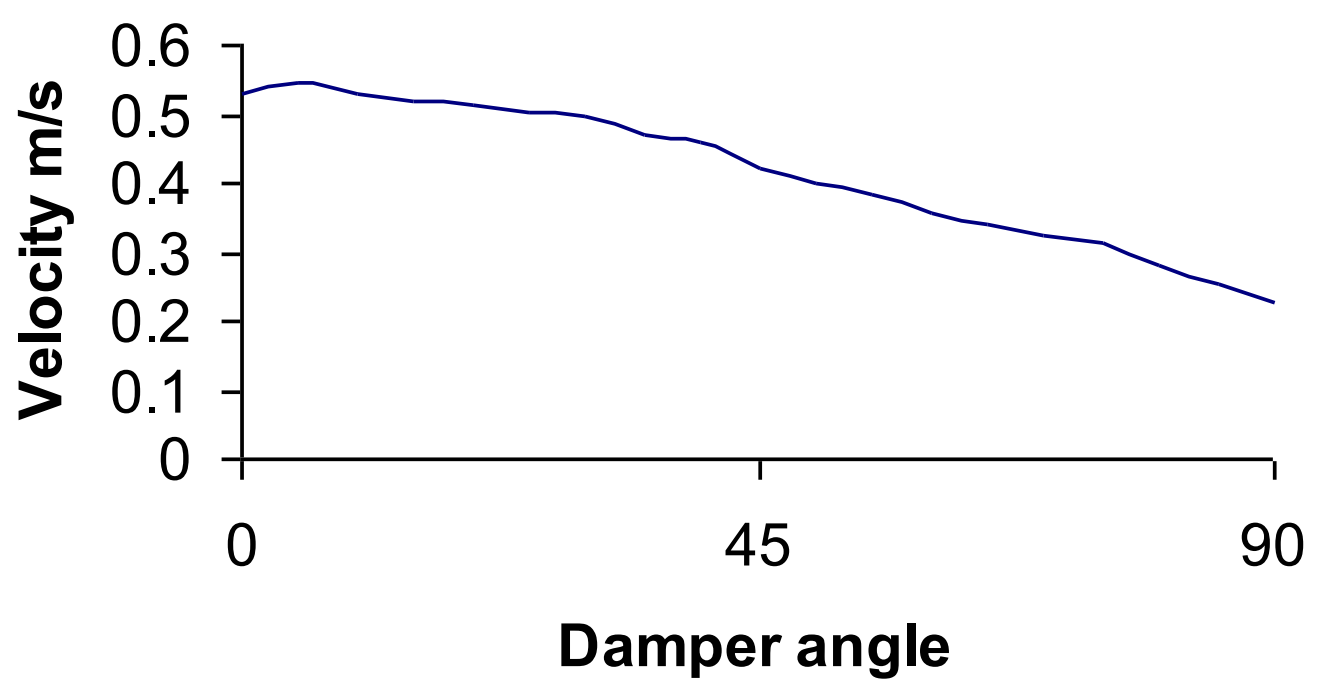

Figure 24 Effect on Windvent delivered air velocity by an increase in damper angle 


\section{Dampers Investigation}

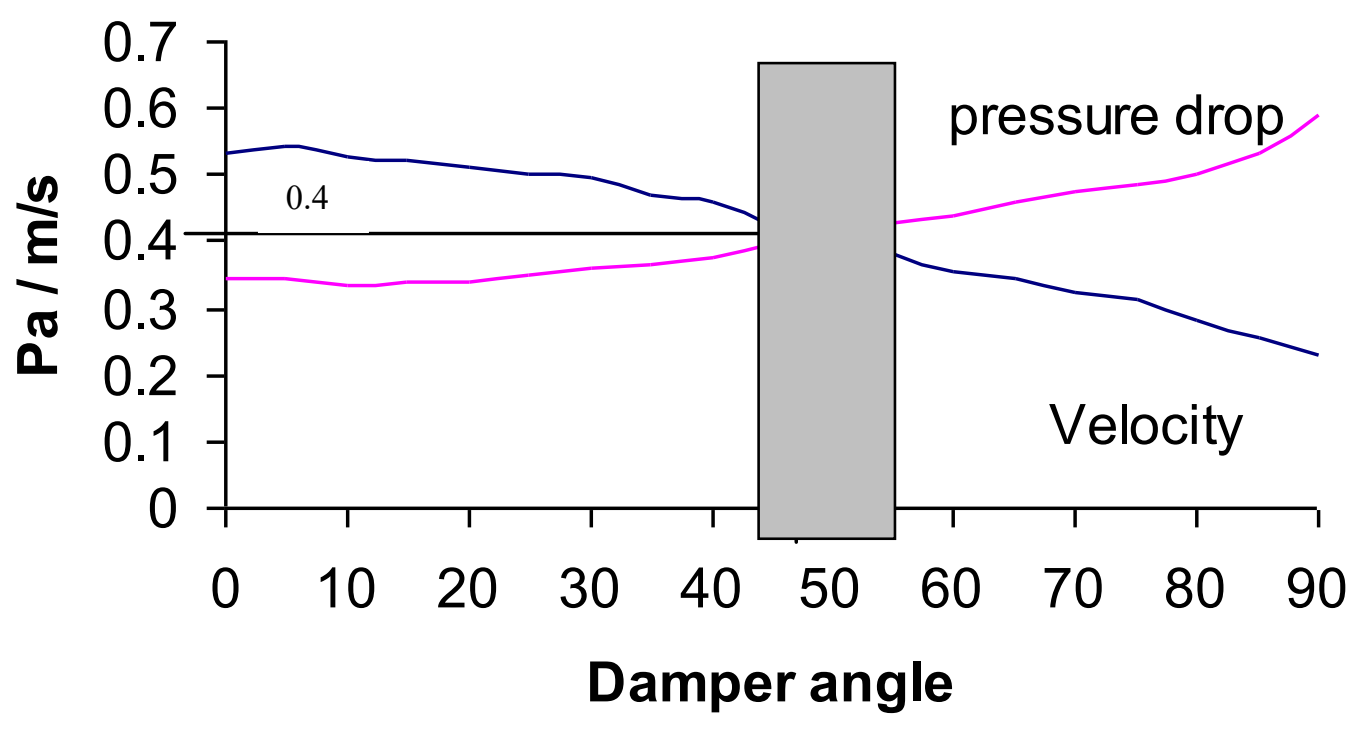

Figure 25 The combined effects on Windvents velocity and pressure by an increase in damper angle

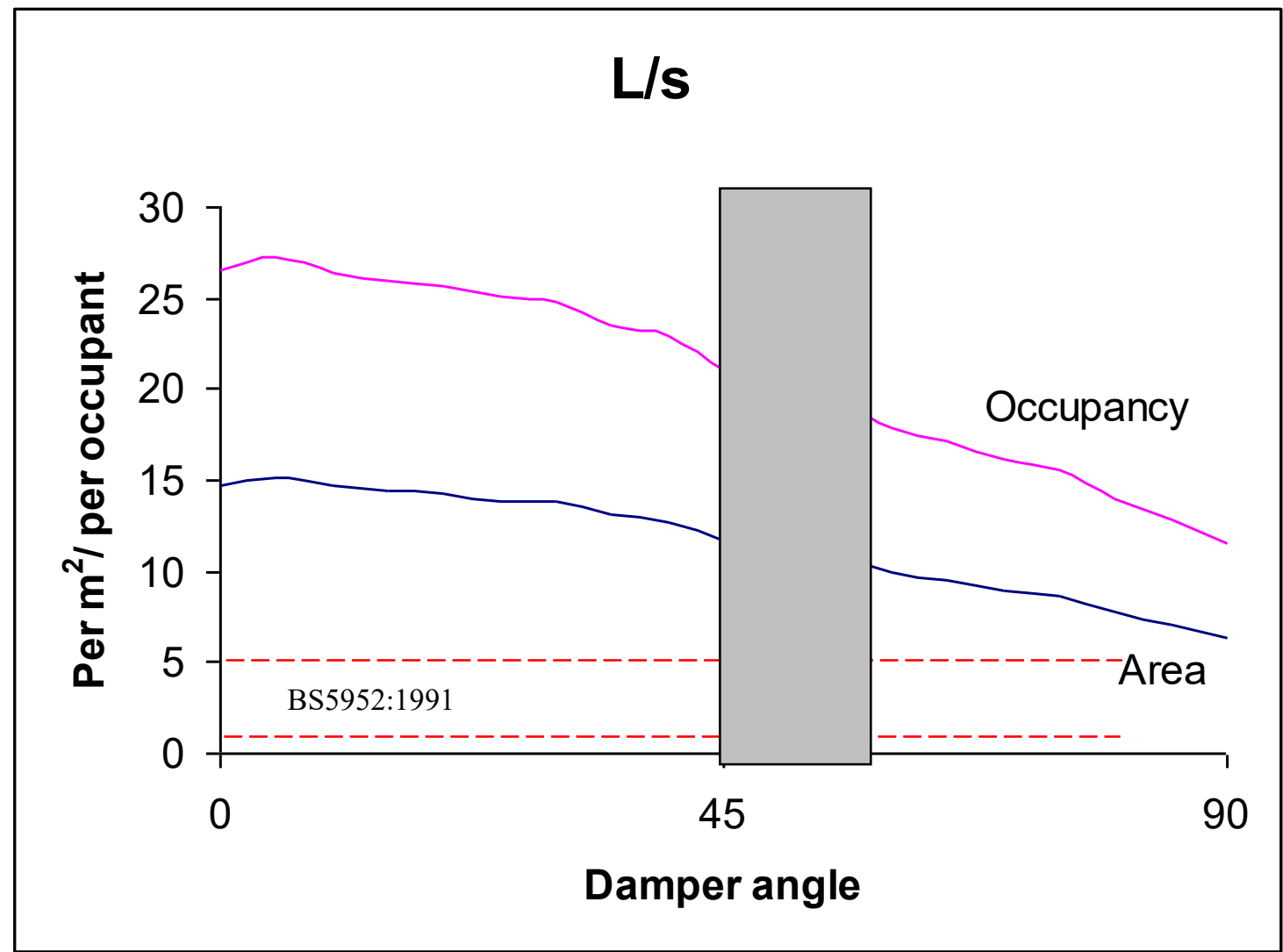

Figure 26 The effect on Windvents fresh air delivery rates by an increase in damper angle 


\subsection{Discussion}

The complete results recorded from the 19 CFD models at each incident angle increment may be seen in table 1. The results show the converted delivery rates for BS5952:1991 comparison as well as the CFD fluid flow velocity in $\mathrm{m} / \mathrm{s}$.

The 19 CFD models were run with identical boundary conditions, with the damper incident angle varied in 5 degree increments. The external wind velocity remained constant at 4.5 $\mathrm{m} / \mathrm{s}$ as this is the UK average wind speed.

Figure 23 shows that as the angle of the dampers increases, the pressure drop also increases. This is as anticipated as the dampers are restricting the flow path and thus creating a greater resistance at P1. Overall, a 73\% increase in the recorded pressure drop is observed over the range of incident angles.

Figure 24 shows that as the damper angle increases, the delivered velocity is reduced. Again this was expected, as the flow is restricted, thus less air flow reaches the diffuser and may be delivered into the room. The dampers reduced the delivered velocity by $43 \%$ over the range of incident angles.

The first two charts confirmed the anticipated results of restricting the airflow by adjusting the damper angle. The pressure drop may be described in terms of controlling the movement of the airflow, and the velocity as controlling the rate of the airflow. Therefore a combination of the two is used to describe the behaviour of the airflow.

Superimposing Figures 23 and 24 to create figure 25 illustrates the combined response of the pressure and velocity due to damper incident angle variations. The intersection of the two trend lines represents the optimum incident angle for the dampers, and appears at 48 degrees at $0.4 \mathrm{~Pa}$.

Although Figure 25 shows an optimum angle of 48 degrees, it should be noted that fixing the damper angle at this position is not possible due to the continuous change in external velocity variations. However the aim of the dampers control strategy is to minimise their movement, thus maintaining a constant delivery rate. By examining Figure 25, an operating envelope around 48 degrees, between 45 - 55 degrees would increase the likelihood of optimum delivery conditions, and should be the target range for this type of application.

The current British standards BS5952:1991 [11] stipulate minimum and recommended delivery rates for ventilation devices in terms of $\mathrm{L} / \mathrm{s}$ per occupant and per $\mathrm{m}^{2}$. For the purpose of this comparison the occupancy levels have been set at 20, as recommended in Building Bulletin 98 [15]. Figure 24 illustrates the delivery rates for comparison with current recommendations. The recommended minimum rate per occupant is $5 \mathrm{~L} / \mathrm{s}$, whilst the rate per $\mathrm{m}^{2}$ is $0.8 \mathrm{~L} / \mathrm{s}$.

Figure 26 shows that delivery rates exceed the recommended minimum and require damping to ensure over ventilation does not occur which may lead to occupant's discomfort. It should be noted that 90 degrees the dampers would be fully closed and in theory the delivery rate should be zero. The dampers in reality should fully close to achieve the theoretical zero delivery rate, as they are a sealed unit. However in the CFD model it is 
not possible to represent this airtight seal, and so the results allowed for some leakage which accounts for the higher than theoretical delivery rates at 90 degrees.

\subsection{Conclusion}

The Windvent performed as expected in terms of pressure drop and velocity when the dampers angle was increased. The combined effects of pressure and velocity showed an optimum operating range of between 45 - 55 degrees.

The optimum operating range should be central to the operating strategy for the windvent as a single unit. However in order to obtain efficient usage of the windvent system the strategy must take into account the external wind velocities. Therefore when locating the size and amount of Windvents (multiple units may be used to supply large areas) a combined approach of macro to micro climate performance and control strategy should be employed.

The CFD results show good correlation, and the grid adaption technique is a well recognised practice for achieving reliable results with the chosen software. Previous works have illustrated the potential of the software for this application, however to verify the results experimental testing will take place and the results shared in future publications.

\section{Acknowledgements}

The authors would like to acknowledge the support of EPSRC, Midtherm, Naturally Driven Ltd and The Whitworth Society in carrying out this investigation. 


\section{References}

1 FATHY, H. (1986). Natural energy and vernacular architecture, principles and examples with reference to hot arid climates. London, University of Chicago press.

2 SANTAMOURIS, M. (2002). Natural ventilation in buildings A design handbook. United Kingdom, Cromwell Press.

3 Hughes, B. R. and Ghani, S.A.A (2007). Investigation of a Windvent Passive Ventilation Device against Current Fresh Air Supply Recommendations.

4 HUNT, G. R. and LINDEN, P. F. (1999). The fluid mechanics of natural ventilation - displacement ventilation by buoyancy - driven flows assisted by wind. Building and environment, 34 707-720.

5 DRORI, U. and ZISKIND, G. (2004). Induced ventilation of a one-story real-size building. Energy and buildings, 36 881-890.

6 PRIYADARSINI, R., CHEONG, K. W. and WONG, N. H. (2004). Enhancement of natural ventilation in high-rise residential buildings using stack system. Energy and buildings, 36 61-71.

7 ELMUALIM, Abbas A. (2006/8). Effect of damper and heat source on wind catcher natural ventilation performance. Energy and buildings, 38 (8), 939-948.

8 ELMUALIM, Abbas A. (2006). Failure of a control strategy for a hybrid airconditioning and wind catchers/towers system at Bluewater shopping malls in Kent, UK. Emerald 24 399-411.

9 LI, Liu and MAK, C. M. (2007). The assessment of the performance of a windcatcher system using computational fluid dynamics. Building and environment, 42 (3), 1135- 1141.

10 SU, Yuehong, et al. Experimental and CFD study of ventilation flow rate of a monodraught ${ }^{\mathrm{TM}}$ windcatcher. Energy and buildings, 2007.

11 British Standards(1991). Ventilation principles and designing for natural ventilation. BS5925:1991.

12 FLUENT. Fluent user manual 6.2(2003). Fluent Incorporated.

13 CHUNG, T. J. (2002). Computational fluid dynamics. Cambridge, University press. 
14 ELMUALIM, Abbas A. a. e. a. u.(2006). Dynamic modelling of a wind catcher/tower turret for natural ventilation. Building services engineering research and technology, 27 (3), 165-182.

15 Department for Education and Skills Briefing framework for secondary school projects(2006). Building Bulletin 98. United Kingdom. 